Atmos. Chem. Phys., 18, 10931-10954, 2018

https://doi.org/10.5194/acp-18-10931-2018

(C) Author(s) 2018. This work is distributed under

the Creative Commons Attribution 4.0 License.

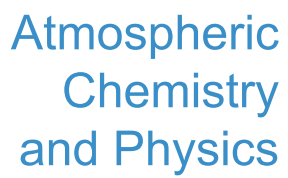

(c) (P)

\title{
Spatial-temporal patterns of inorganic nitrogen air concentrations and deposition in eastern China
}

\author{
Wen Xu ${ }^{1,2}$, Lei Liu ${ }^{3}$, Miaomiao Cheng ${ }^{4}$, Yuanhong Zhao ${ }^{5}$, Lin Zhang ${ }^{5}$, Yuepeng Pan ${ }^{6}$, Xiuming Zhang ${ }^{7}$ Baojing Gu $^{8}$, \\ Yi Li ${ }^{9}$, Xiuying Zhang ${ }^{3}$, Jianlin Shen ${ }^{10}$, Li Lu ${ }^{11}$, Xiaosheng Luo ${ }^{12}$, Yu Zhao ${ }^{13}$, Zhaozhong Feng ${ }^{2}$, \\ Jeffrey L. Collett Jr. ${ }^{14}$, Fusuo Zhang ${ }^{1}$, and Xuejun Liu ${ }^{1}$ \\ ${ }^{1}$ College of Resources and Environmental Sciences, Key Laboratory of Plant-Soil Interactions of MOE, Beijing Key \\ Laboratory of Cropland Pollution Control and Remediation, China Agricultural University, Beijing 100193, China \\ ${ }^{2}$ State Key Laboratory of Urban and Regional Ecology, Research Center for Eco-Environmental Sciences, \\ Chinese Academy of Sciences, Shuangqing Road 18, Haidian District, Beijing 100085, China \\ ${ }^{3}$ Jiangsu Provincial Key Laboratory of Geographic Information Science and Technology, International Institute for Earth \\ System Science, Nanjing University, Nanjing 210023, China \\ ${ }^{4}$ State Key Laboratory of Environmental Criteria and Risk Assessment, Chinese Research Academy of Environmental \\ Sciences, Beijing 100012, China \\ ${ }^{5}$ Laboratory for Climate and Ocean-Atmosphere Sciences, Department of Atmospheric and Oceanic Sciences, \\ School of Physics, Peking University, Beijing 100871, China \\ ${ }^{6}$ State Key Laboratory of Atmospheric Boundary Layer Physics and Atmospheric Chemistry (LAPC), \\ Institute of Atmospheric Physics, Chinese Academy of Sciences, Beijing 100029, China \\ ${ }^{7}$ School of Agriculture and Food Sciences, The University of Melbourne, Victoria, 3010, Australia \\ ${ }^{8}$ Department of Land Management, Zhejiang University, Hangzhou 310058, China \\ ${ }^{9}$ Arizona Department of Environmental Quality, Phoenix, AZ 85007, USA \\ ${ }^{10}$ Institute of Subtropical Agriculture, Chinese Academy of Sciences, Changsha 410125, China \\ ${ }^{11}$ Institute of Surface-Earth System Science, Tianjin University, Tianjin 300072, China \\ ${ }^{12}$ Institute of Plant Nutrition, Resources and Environmental Sciences, Henan Academy of Agricultural Sciences, \\ Henan Key Laboratory of Agricultural Eco-environment, Zhengzhou 450002, China \\ ${ }^{13}$ State Key Laboratory of Pollution Control \& Resource Reuse, School of the Environment, Nanjing University, \\ 163 Xianlin Ave., Nanjing, Jiangsu 210023, China \\ ${ }^{14}$ Department of Atmospheric Science, Colorado State University, Fort Collins, Colorado, 80523 USA
}

Correspondence: Xuejun Liu (liu310@cau.edu.cn) and Zhaozhong Feng (fzz@ rcees.ac.cn)

Received: 26 April 2018 - Discussion started: 15 May 2018

Revised: 11 July 2018 - Accepted: 17 July 2018 - Published: 6 August 2018

\begin{abstract}
Five-year (2011-2015) measurements of gaseous $\mathrm{NH}_{3}, \mathrm{NO}_{2}$, and $\mathrm{HNO}_{3}$ and particulate $\mathrm{NH}_{4}^{+}$and $\mathrm{NO}_{3}^{-}$in air and/or precipitation were conducted at 27 sites in the Nationwide Nitrogen Deposition Monitoring Network (NNDMN) to better understand spatial and temporal (seasonal and annual) characteristics of reactive nitrogen $\left(\mathrm{N}_{\mathrm{r}}\right)$ concentrations and deposition in eastern China. Our observations reveal annual average concentrations $\left(16.4-32.6 \mu \mathrm{g} \mathrm{N} \mathrm{m}^{-3}\right)$, dry deposition fluxes (15.8-31.7 $\left.\mathrm{kg} \mathrm{N} \mathrm{ha}^{-1} \mathrm{yr}^{-1}\right)$, and wet/bulk deposition fluxes (18.4-28.0 $\mathrm{kg} \mathrm{N} \mathrm{ha}^{-1} \mathrm{yr}^{-1}$ ) based on land use,
\end{abstract}

ranked as urban > rural > background sites. Annual concentrations and dry deposition fluxes of each $\mathrm{N}_{\mathrm{r}}$ species in air were comparable at urban and background sites in northern and southern regions, but were significantly higher at northern rural sites. These results, together with good agreement between spatial distributions of $\mathrm{NH}_{3}$ and $\mathrm{NO}_{2}$ concentrations determined from ground measurements and satellite observations, demonstrate that atmospheric $\mathrm{N}_{\mathrm{r}}$ pollution is heavier in the northern region than in the southern region. No significant inter-annual trends were found in the annual $\mathrm{N}_{\mathrm{r}}$ dry 
and wet/bulk $\mathrm{N}$ deposition at almost all of the selected sites. A lack of significant changes in annual averages between the 2013-2015 and 2011-2012 periods for all land use types suggests that any effects of current emission controls are not yet apparent in $\mathrm{N}_{\mathrm{r}}$ pollution and deposition in the region. Ambient concentrations of total $\mathrm{N}_{\mathrm{r}}$ exhibited non-significant seasonal variation at all land use types, although significant seasonal variations were found for individual $\mathrm{N}_{\mathrm{r}}$ species (e.g. $\mathrm{NH}_{3}, \mathrm{NO}_{2}$, and $p \mathrm{NO}_{3}^{-}$) in most cases. In contrast, dry deposition of total $\mathrm{N}_{\mathrm{r}}$ exhibited a consistent and significant seasonal variation at all land use types, with the highest fluxes in summer and the lowest in winter. Based on sensitivity tests by the GEOS-Chem model, we found that $\mathrm{NH}_{3}$ emissions from fertilizer use (including chemical and organic fertilizers) were the largest contributor ( $36 \%$ ) to total inorganic $\mathrm{N}_{\mathrm{r}}$ deposition over eastern China. Our results not only improve the understanding of spatial-temporal variations of $\mathrm{N}_{\mathrm{r}}$ concentrations and deposition in this pollution hotspot, but also provide useful information for policy-makers that mitigation of $\mathrm{NH}_{3}$ emissions should be a priority to tackle serious $\mathrm{N}$ deposition in eastern China.

\section{Introduction}

In China, and globally, human activities have dramatically increased emissions of nitrogen oxides $\left(\mathrm{NO}_{x}=\mathrm{NO}+\mathrm{NO}_{2}\right)$ and ammonia $\left(\mathrm{NH}_{3}\right)$ into the atmosphere since the beginning of the industrial revolution (Galloway et al., 2008; Liu et al., 2013). $\mathrm{NO}_{x}$ and $\mathrm{NH}_{3}$ emitted into the atmosphere are transformed to nitrogen-containing particles (e.g. particulate $\mathrm{NH}_{4}^{+}$ and $\mathrm{NO}_{3}^{-}$, and organic nitrogen; Ianniello et al., 2010; Zhang et al., 2015), which are major chemical constituents of airborne $\mathrm{PM}_{2.5}$ (particulate matter with a diameter of $2.5 \mu \mathrm{m}$ or less) and have implications for air quality and climate (Fuzzi et al., 2015). As a result of elevated reactive nitrogen $\left(\mathrm{N}_{\mathrm{r}}\right)$ emissions, nitrogen $(\mathrm{N})$ deposition through dry and wet processes has also substantially increased over China (Liu et al., 2013; Lu et al., 2007, 2014; Jia et al., 2014, 2016), and excessive deposition of $\mathrm{N}$ has resulted in detrimental impacts including decreased biological diversity (Bobbink et al., 2010), nutrient imbalance (Li et al., 2016), increased soil acidification (Yang et al., 2015), and eutrophication of water bodies (Fenn et al., 2003). Furthermore, $\mathrm{N}_{\mathrm{r}}$-associated haze pollution episodes, characterized by high concentrations of $\mathrm{PM}_{2.5}$, occur frequently in China, as evidenced in particular in 2013 (Guo et al., 2014; Huang et al., 2014; Tian et al., 2014).

In order to control its notorious air pollution, China has reduced national emissions of $\mathrm{SO}_{2}$ and particulate matter by 14 and $30 \%$ respectively from 2005 to 2010 (MEPC, 2011). Additionally, stringent measures (e.g. using selective catalytic/non-catalytic reduction systems, and implementing tighter vehicle emission standards) were implemented during the 12th Five Year Plan (FYP) period (2011-2015), with aims to reduce 2015 annual emissions of $\mathrm{SO}_{2}$ and $\mathrm{NO}_{x}$ by 8 and $10 \%$ respectively relative to 2010 levels (Xia et al., 2016). However, there is as yet no regulation or legislation that deals with national $\mathrm{NH}_{3}$ emissions and thus the emission reductions of $\mathrm{SO}_{2}$ and $\mathrm{NO}_{x}$ used to achieve desired air-quality improvement goals will be compromised (Gu et al., 2014). Significant increases in $\mathrm{PM}_{2.5}$ concentrations have been observed in the years 2013 and 2014 as compared to 2012, excluding the influence of meteorological conditions on inter-annual variations (Liang et al., 2015). Other studies with more conclusive evidence have likewise suggested that $\mathrm{NH}_{3}$ plays a vital role in sulfate formation and exacerbates severe haze pollution development in urban regions of China (Wang et al., 2016), even acting as the key limiting factor for the formation of secondary inorganic aerosol (Wu et al., 2016). In addition, due to higher local and regional concentrations of $\mathrm{NH}_{3}$ in the atmosphere, nitrate-driven haze pollution occurred during summertime in urban environment in the North China Plain (Li et al., 2018). The absolute and relative concentrations of particulate nitrate in urban Beijing increased with haze development (Pan et al., 2016). Also, nitrate contributed to a large fraction of the elevated $\mathrm{PM}_{2.5}$ concentrations at a rural site in the North China Plain and high $\mathrm{NH}_{3}$ in the early morning accelerated the formation of fine nitrates (Wen et al., 2015).

High rates of $\mathrm{N}$ deposition have also been observed during 2011-2014 across China (Xu et al., 2015). However, to date, no study based on long-term ground-based observations has provided any information on the effectiveness of $\mathrm{SO}_{2}$ and $\mathrm{NO}_{x}$ emission controls on $\mathrm{N}$ deposition in China. Non-linearities have been identified between reductions in emissions and deposition in Europe over the last 3 decades (Aguillaume et al., 2016; Fowler et al., 2007). Due to the tightly coupled yet complex relationship between emissions, concentrations, and deposition, long-term monitoring networks can test the effectiveness of emission controls (Erisman et al., 2003). Currently two national $\mathrm{N}$ deposition networks are operational in China, i.e. the Nationwide Nitrogen Deposition Monitoring Network (NNDMN, Liu et al., 2011; Xu et al., 2015) and the Chinese Ecosystem Research Network (CERS, Zhu et al., 2015). The NNDMN, containing 43 in situ monitoring sites, has been measuring wet $\mathrm{N}$ deposition and ambient concentrations of five major $\mathrm{N}_{\mathrm{r}}$ species (i.e. gaseous $\mathrm{NH}_{3}, \mathrm{NO}_{2}$, and $\mathrm{HNO}_{3}$, and particulate $\mathrm{NH}_{4}^{+}$ and $\mathrm{NO}_{3}^{-}$) since 2010 , the latter species for subsequent estimation of dry deposition. The CERS was established in 1988 and has been mainly focused on wet $\mathrm{N}$ deposition at 41 field stations. In addition to ground-based measurements, satellite observations enable retrieval of atmospheric $\mathrm{NH}_{3}$ and $\mathrm{NO}_{2}$ with high temporal and spatial resolutions (Dammer et al., 2016; Russell et al., 2012), providing a means to reveal spatial distributions and long-term trends of ambient $\mathrm{NH}_{3}$ and $\mathrm{NO}_{2}$ levels at regional to global scales, and also to evaluate the effectiveness of emission controls (Krotkov et al., 2016). However, to effectively use the vast satellite data sets for en- 
vironmental monitoring, it is critical to validate these remote sensing observations using in situ surface observations (Pinder et al., 2011; Van Damme et al., 2015).

Eastern China is a developed region with the largest densities of population, economic activity, and resource consumption in the country (He et al., 2015). Recent satellite observations indicate that tropospheric $\mathrm{NH}_{3}$ and $\mathrm{NO}_{2}$ levels in eastern China were both much greater than other regions of the world over 2005-2015 (Demmer et al., 2016; Krotkov et al., 2016). Accordingly, this region received the highest levels of dry $\mathrm{N}$ deposition in the world (Vet et al., 2014), and was regarded as a primary export region of $\mathrm{N}$ deposition to neighbouring countries (Ge et al., 2014). Based on meta-analysis of published observations, some studies have provided information on the magnitudes, spatial distributions, and decadal variations of wet/bulk $\mathrm{N}$ deposition in China (Liu et al., 2013; Jia et al., 2014), but the analysed data were limited to time periods between 1980 and 2010. Although a recent study (Jia et al., 2016) has reported a clear increasing trend of dry $\mathrm{N}$ deposition in eastern China between 2005 and 2014, considerable uncertainty may exist due to estimates of gaseous $\mathrm{HNO}_{3}$ and particulate $\mathrm{NH}_{4}^{+}$and $\mathrm{NO}_{3}^{-}\left(p \mathrm{NH}_{4}^{+}\right.$and $\left.p \mathrm{NO}_{3}^{-}\right)$ concentrations using $\mathrm{NO}_{2}$ satellite data, which is in part manifested in Liu et al. (2017a). Furthermore, seasonal patterns of $\mathrm{N}_{\mathrm{r}}$ concentrations and deposition have not yet been systematically investigated at a large spatial scale in this region, although spatial patterns of dry $\mathrm{N}_{\mathrm{r}}$ deposition for representative months of four seasons (i.e. January for winter, April for spring, July for summer, October for autumn) in 2010 have been mapped with the RAMS-CMAQ model (Han et al., 2017). Thus, the spatial and temporal (annual and seasonal) variations of $\mathrm{N}_{\mathrm{r}}$ concentrations and dry and wet deposition in eastern China require further exploration using groundbased measurements, especially for time periods after 2010 . Our previous work (Xu et al., 2015) used multi-year measurements (mainly from January 2010 to September 2014) at the 43 sites in the NNDMN, aiming to provide the first quantitative information on atmospheric $\mathrm{N}_{\mathrm{r}}$ concentrations and pollution status across China, and to analyse overall fluxes and spatial variations of $\mathrm{N}_{\mathrm{r}}$ deposition in relation to anthropogenic $\mathrm{N}_{\mathrm{r}}$ emissions from six regions.

The present study aims to examine spatial-temporal (annual and seasonal) characteristics of $\mathrm{N}_{\mathrm{r}}$ concentrations in air $\left(\mathrm{NH}_{3}, \mathrm{NO}_{2}, \mathrm{HNO}_{3}, p \mathrm{NH}_{4}^{+}\right.$, and $\left.p \mathrm{NO}_{3}^{-}\right)$and precipitation $\left(\mathrm{NH}_{4}^{+}-\mathrm{N}\right.$ and $\left.\mathrm{NO}_{3}^{-}-\mathrm{N}\right)$, and their corresponding dry and wet/bulk $\mathrm{N}$ deposition, through a 5-year (2011-2015) monitoring period at 27 NNDMN sites in eastern China. In addition, we compare spatial-temporal variability of measured $\mathrm{NH}_{3}$ and $\mathrm{NO}_{2}$ concentrations with variations of the corresponding satellite retrieval columns, as well as interannual trends in $\mathrm{N}_{\mathrm{r}}$ deposition and emissions. Finally, emission sources contributing to total $\mathrm{N}$ deposition over eastern China are examined.

\section{Materials and methods}

\subsection{Study area and site descriptions}

The present study was conducted in eastern China, which is distinguished by the "Hu Line" (She, 1998). This region has spatial heterogeneity in levels of economic development, and significant spatial differences in $\mathrm{NH}_{3}$ and $\mathrm{NO}_{x}$ emissions (Fig. 1b and c). Thus, to better analyse spatial and temporal variabilities in measured $\mathrm{N}_{\mathrm{r}}$ concentrations and deposition, we divided eastern China into northern and southern regions using the Qinling Mountains-Huaihe River line (Fig. 1a), the division basin of which was based on the differences in natural conditions, agricultural production, geographical features, and lifestyle. As for specific differentiations, for example, the northern region adopted a centralized domestic heating policy for late autumn and winter seasons but the south has not; annual average precipitation amounts were generally greater than $800 \mathrm{~mm}$ in the south but were less than $800 \mathrm{~mm}$ in the north. In addition, the north is dominated by calcareous soils, which could result in higher soil $\mathrm{NH}_{3}$ volatilization (Huang et al., 2015), vs. the acidic red soil in the south.

The NNDMN was operated in line with international standards by China Agricultural University (CAU); 35 NNDMN sites were located in eastern China (Xu et al., 2015). For our analysis, we considered 27 sites in total, with 5-year continuous data: 13 sites were located in north of the Qinling Mountains-Huaihe River line (China Agricultural University: CAU, Zhengzhou: ZZ, Dalian: DL, Shangzhuang: SZ, Quzhou: QZ, Yangqu: YQ, Zhumadian: ZMD, Yanglin: YL, Yucheng: YC, Gongzhuling: GZL, Lishu: LS, Lingshandao: LSD, Changdao: CD), and 14 sites were located in south of the line (Nanjing: NJ, Baiyun: BY, Wenjiang: WJ, Wuxue: WX, Taojing: TJ, Fengyang: FYA, Zhanjiang: ZJ, Fuzhou: FZ, Fenghua: FH, Ziyang: ZY, Yangting: YT, Jiangjin: JJ, Huinong: HN, Xishan: XS).

All the sites are located as far away as possible and practical from local direct emission sources to increase regional representativeness. They can be divided into three categories according to their geopolitical location and their proximity to the main emission sources: urban sites (abbreviated as U), rural sites (cropland areas, R), and background sites (coastal and forest areas, B). Information on the monitoring sites, such as land use types, coordinates, and measurement periods are listed in Table S1 of the Supplement. Detailed descriptions of all the sites including the surrounding environment and nearby emission sources can be found in Xu et al. (2015).

\subsection{Field sampling and chemical analysis}

Continuous measurements were performed during the period from January 2011 to December 2015 at the 27 study sites, except for 11 sites (ZZ, ZMD, YC, LSD, NJ, WX, FYA, ZJ, YT, JJ, and HN), where field sampling was carried out after the year 2011 (i.e. the years between 2012 and 2015) 


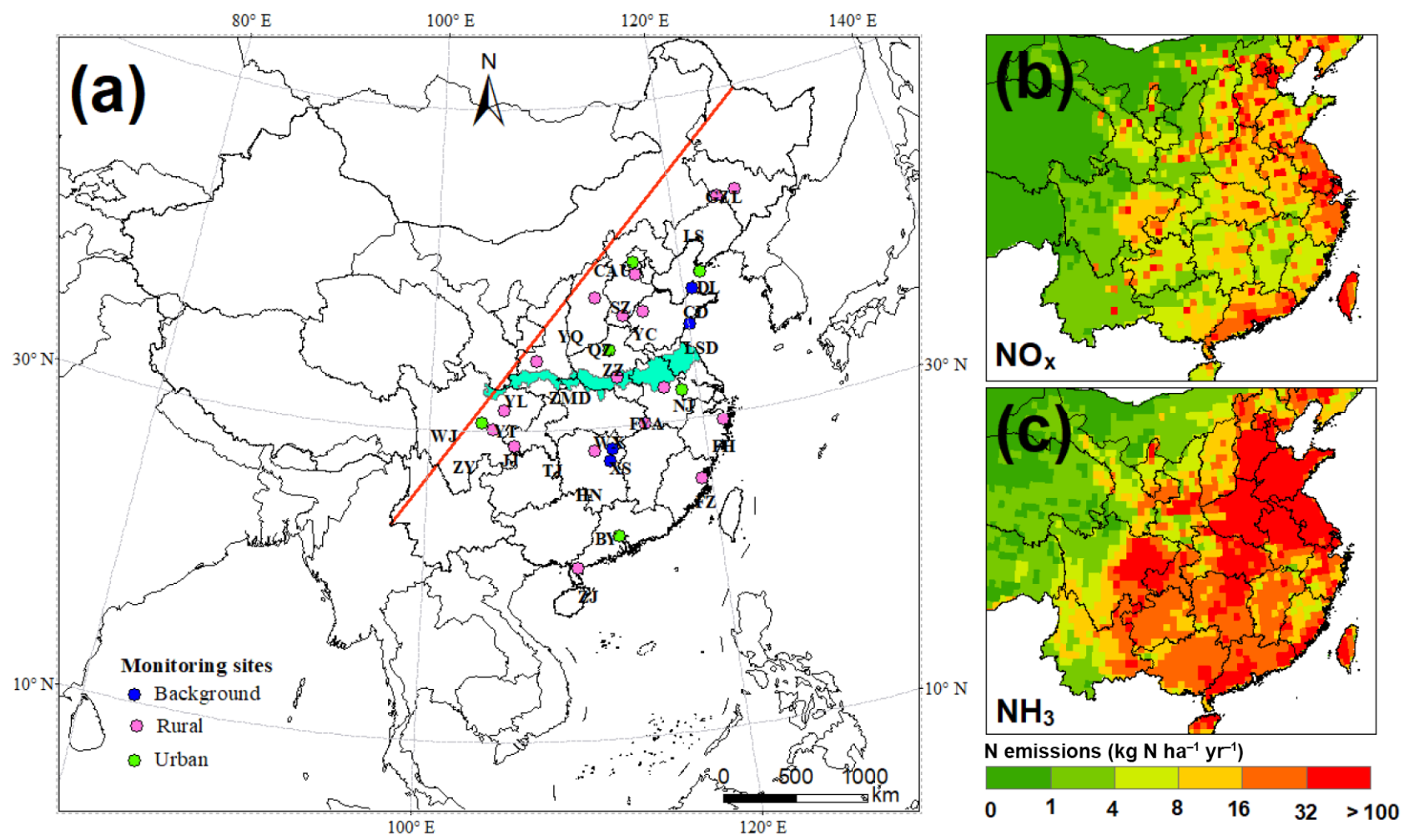

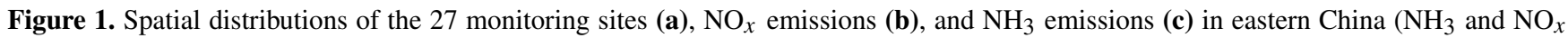
emission data were for the year 2010 and obtained from Liu et al., 2017b). The blue and red lines refer to the Qinling-Huaihe line, and Hu line respectively.

and/or interrupted during the period due to instrument failure (details in Table S1, Supplement). Ambient $\mathrm{N}_{\mathrm{r}}$ concentrations of gaseous $\mathrm{NH}_{3}$ and $\mathrm{HNO}_{3}$, and $p \mathrm{NH}_{4}^{+}$and $p \mathrm{NO}_{3}^{-}$ (for which the empirically determined effective size cut-off for aerosol sampling is of the order of $4.5 \mu \mathrm{m}$ ), were measured using an active DELTA (DEnuder for Long-Term Atmospheric sampling; Tang et al., 2009) system; gaseous $\mathrm{NO}_{2}$ was sampled in three replicates with passive diffusion tubes (Gradko International Limited, UK). The air intakes of the DELTA system and the $\mathrm{NO}_{2}$ tubes were mounted $2 \mathrm{~m}$ above the ground at most sites and protected from precipitation and direct sunlight with a rigid plastic box and a PVC shelter respectively. All measurements of $\mathrm{N}_{\mathrm{r}}$ concentration were based on monthly sampling (one sample per month for each $\mathrm{N}_{\mathrm{r}}$ species). Detailed information on measuring methods and collection are given in Sect. S1 of the Supplement.

To collect precipitation (here termed as wet/bulk deposition, which contains wet and some dry deposition due to the use of an open sampler) samples, a standard precipitation gauge (SDM6, Tianjin Weather Equipment Inc., China) was continuously exposed beside the DELTA system $(\sim 2 \mathrm{~m})$. Immediately after each precipitation event (08:00-08:00 the following day, Greenwich Mean Time +8), samples (including rain and melted snow) were collected and stored in clean polyethylene bottles $(50 \mathrm{~mL})$ at $-18^{\circ} \mathrm{C}$ until sent to the $\mathrm{CAU}$ laboratory for analysis. Each collector was rinsed three times with high-purity water after each collection.

In the analytical laboratory, acid-coated denuders and aerosol filters were extracted with 6 and $10 \mathrm{~mL}$ of high-purity water $(18.2 \mathrm{M} \Omega)$ respectively and analysed for $\mathrm{NH}_{4}^{+}-\mathrm{N}$ with an AA3 continuous-flow analyser (CFA; BranC Luebbe $\mathrm{GmbH}$, Norderstedt, Germany). Carbonate-coated denuders and filters were both extracted with $10 \mathrm{~mL} 0.05 \% \mathrm{H}_{2} \mathrm{O}_{2}$ solution followed by analysis of $\mathrm{NO}_{3}-\mathrm{N}$ using the same CFA. $\mathrm{NO}_{2}$ samples, extracted with a solution containing sulfanilamide, $\mathrm{H}_{3} \mathrm{PO}_{4}$, and $\mathrm{N}$-1-naphthylethylene-diamine, were determined using a colorimetric method by absorption at a wavelength of $542 \mathrm{~nm}$ (Xu et al., 2016). Precipitation samples were filtered through a syringe filter $(0.45 \mathrm{~mm}$; Tengda Inc., Tianjin, China) and analysed for $\mathrm{NH}_{4}^{+}-\mathrm{N}$ and $\mathrm{NO}_{3}^{-}-\mathrm{N}$ using the CFA as mentioned above. Quality assurance and quality control procedures adopted in the analytical laboratory are described by $\mathrm{Xu}$ et al. (2017). Further details of precipitation measurement, samples handling, and chemical analysis are reported in Xu et al. (2015).

\subsection{Deposition estimate}

Wet/bulk deposition of $\mathrm{NH}_{4}^{+}-\mathrm{N}$ and $\mathrm{NO}_{3}^{-}-\mathrm{N}$ were calculated per month and year by multiplying the precipitation amount 
by their respective volume-weighted mean (VWM) concentrations. The dry deposition flux of gaseous and particulate $\mathrm{N}_{\mathrm{r}}$ species was calculated as the product of measured concentrations by modelled deposition velocities $\left(V_{\mathrm{d}}\right)$. The dry deposition velocities of five $\mathrm{N}_{\mathrm{r}}$ species were calculated by the GEOS (Goddard Earth Observing System)-Chem chemical transport model (CTM; Bey et al., 2001; http://geos-chem. org), and have been reported in a companion paper ( $\mathrm{Xu}$ et al., 2015). In brief, the model calculation of dry deposition of $\mathrm{N}_{\mathrm{r}}$ species follows a standard big-leaf resistance-in-series model as described by Wesely (1989) for gases and Zhang et al. (2001) for aerosol. We used archived hourly $V_{\mathrm{d}}$ from January 2011 to May 2013 and filled the gap for the period (from June 2013 to December 2015) when GEOS meteorological data are unavailable using the mean values calculated from all the available simulations. The monthly $V_{\mathrm{d}}$ at each site was averaged from the hourly data set.

\subsection{Satellite retrievals of $\mathrm{NH}_{3}$ and $\mathrm{NO}_{2}$}

Comparisons between satellite observations and groundbased measurements were evaluated at the 27 sites in order to accurately examine the spatial-temporal pattern of $\mathrm{NH}_{3}$ and $\mathrm{NO}_{2}$ concentrations. For $\mathrm{NH}_{3}$, we used the products retrieved from the Infrared Atmospheric Sounding Interferometer (IASI) instrument (aboard the MetOp-A platform), which crosses the equator at a mean local solar time of 09:30 and 21:30. The IASI-NH 3 product is based on the calculation of a spectral hyperspectral range index and subsequent conversion to $\mathrm{NH}_{3}$ total columns via a neural network. The details of the IASI-NH 3 retrieval method are described in Whitburn et al. (2016). We only considered the observations from the morning overpass as they are generally more sensitive to $\mathrm{NH}_{3}$ because of higher thermal contrast at this time of day (Van Damme et al., 2015; Dammers et al., 2016). The daily IASI-NH 3 data (provided by the Atmospheric Spectroscopy Group at Université Libre De Bruxelles; data available at http://iasi.aeris-data.fr/NH3/) from 1 January 2011 to 31 December 2015 was used for the spatial analysis in the present study. For the temporal analysis, we used the IASI_NH 3 from 1 January 2011 to 30 September 2014 because an update of the input meteorological data on 30 September 2014 had caused a substantial increase in the retrieved atmospheric $\mathrm{NH}_{3}$ columns. Only observations with a cloud coverage lower than $25 \%$ and relative error lower than $100 \%$, or absolute error smaller than $5 \times 10^{15}$ molecules $\mathrm{cm}^{-2}$, were processed. The methodology is provided in detail in Liu et al. (2017b). In brief, all observations were gridded to a $0.5^{\circ}$ latitude $\times 0.5^{\circ}$ longitude grid, and then we calculated the monthly arithmetic mean by averaging the daily values with observations points within each grid cell. Similarly, we calculated the annual arithmetic mean by averaging the daily values with observations points within the grid cell over the whole year.
For $\mathrm{NO}_{2}$ we used the products from the Ozone Monitoring Instrument (OMI) onboard NASA's EOS-Aura satellite, which was launched in July 2004 into a sun-synchronous orbit with a local equator crossing time at approximately 13:45 OMI detects the backscattered solar radiation from the Earth's atmosphere within the UV-Vis spectral window between 270 and $500 \mathrm{~nm}$, to achieve nearly global coverage daily, with a spatial resolution ranging from $13 \mathrm{~km} \times 24 \mathrm{~km}$ at nadir to $24 \mathrm{~km} \times 128 \mathrm{~km}$ at the edge of the swath (Russell et al., 2012). We used tropospheric $\mathrm{NO}_{2}$ retrievals from the DOMINO (Dutch-Finnish Ozone Monitoring Instrument) algorithm version 2. The retrieval algorithm is described in detail in Boersma et al. (2007). The tropospheric $\mathrm{NO}_{2}$ columns used in this study are monthly means from 1 January 2011 to 30 December 2015 with a spatial resolution of $0.125^{\circ}$ latitude $\times 0.125^{\circ}$ longitude (data available at http: //www.temis.nl/airpollution/no2.html).

\subsection{Statistical analysis}

One-way analysis of variance (ANOVA) and two independent samples $t$ tests were applied to detect significant differences in seasonal mean concentrations and deposition fluxes of measured $\mathrm{N}_{\mathrm{r}}$ species as well as their annual mean deposition fluxes for three land use types (rural, urban, and background). As there was large site-to-site variability in annual $\mathrm{N}_{\mathrm{r}}$ concentrations and deposition fluxes at monitoring sites within the same land use types, averaging data into annual values for land use types is unlikely to be truly representative of actual trends. Thus, annual trends of the variables were evaluated at a single site scale rather than by land use type. Trend analysis was conducted using Theil regression (Theil, 1992) and the Mann-Kendall test (Gilbert, 1987; Marchetto et al., 2013). We defined an increasing (decreasing) trend as a positive (negative) slope of the Theil regression, while a statistical significance level $(p<0.01)$ of a trend was evaluated by the non-parametric Mann-Kendall test ( $p$ value). Nonparametric methods usually have the advantage of being insensitive to outliers, and allow missing data and non-normal distribution of data (Gilbert, 1987; Salmi et al., 2002), appropriate for the analysed data set. The Mann-Kendall method is appropriate for detection of monotonic trends in data series that have no seasonal variation or autocorrelation. Atmospheric concentrations and deposition fluxes of $\mathrm{N}_{\mathrm{r}}$ species, however, generally have distinct seasonal variability (Pan et al., 2012) and the Mann-Kendall test is thus applied to annual values.

Satellite observations during 2005-2015 indicate that tropospheric $\mathrm{NO}_{2}$ levels peaked in 2011 over China (Krotkov et al., 2016; Duncan et al., 2016) and $\mathrm{NO}_{x}$ emissions peaked in 2011/2012 (Miyazaki et al., 2017; van der A et al., 2017; Souri et al., 2017). To assess the impact of emission control measures on measured $\mathrm{N}_{\mathrm{r}}$ concentrations and deposition fluxes at different land use types, we compared arithmetic mean values averaged from the last 3-year pe- 
riod (2013-2015) with those averaged from the first 2-year period (2011-2012) for monitoring sites with continuous 5-year measurements (21 sites for dry, and 17 sites for wet/bulk). Seasonal concentrations and deposition fluxes of measured $\mathrm{N}_{\mathrm{r}}$ species were calculated using the arithmetic average of matched seasons during the sampling periods; spring refers to March-May, summer covers June-August, autumn refers to September-November, and winter covers December-February.

\section{Results}

\subsection{Spatial variability in concentrations of $\mathrm{N}_{\mathbf{r}}$ species in air and precipitation}

Summary statistics of monthly mean concentrations of $\mathrm{NH}_{3}$, $\mathrm{NO}_{2}, \mathrm{HNO}_{3}, p \mathrm{NH}_{4}^{+}$, and $p \mathrm{NO}_{3}^{-}$at the 27 monitoring sites during 2011-2015 are listed in Table S2 of the Supplement. Monthly mean concentrations of $\mathrm{NH}_{3}, \mathrm{NO}_{2}, \mathrm{HNO}_{3}$, $p \mathrm{NH}_{4}^{+}$, and $p \mathrm{NO}_{3}^{-}$ranged over $0.16-39.57$ (TJ and $\mathrm{WJ}$ ), 0.55-29.06 (LS and WJ), 0.04-4.93 (YQ and CAU), 0.1157.20 (ZY and QZ), and $0.01-32.06 \mu \mathrm{g} \mathrm{N} \mathrm{m}{ }^{-3}$ (DL and ZZ) respectively. On the basis of geographical location and classification of each site, the annual mean concentrations of each $\mathrm{N}_{\mathrm{r}}$ species were calculated for three land use types in eastern China and its northern and southern regions (Table 1).

In eastern China, annual mean concentrations of $\mathrm{NH}_{3}$, $\mathrm{NO}_{2}, \mathrm{HNO}_{3}, p \mathrm{NH}_{4}^{+}$, and $p \mathrm{NO}_{3}^{-}$at the urban sites (averages for the 5-year, $1.6 \pm 0.2$ (for $\mathrm{HNO}_{3}$ ) to $10.2 \pm 1.0$ (for $\left.\mathrm{NO}_{2}\right) \mu \mathrm{g} \mathrm{m}^{-3}$ ) increased by $18,70,33,23$, and $43 \%$ respectively compared with their corresponding concentrations at the rural sites $\left(1.2 \pm 1.0\right.$ (for $\mathrm{HNO}_{3}$ ) to $7.2 \pm 0.9$ (for $\left.\mathrm{NH}_{3}\right) \mu \mathrm{g} \mathrm{N} \mathrm{m}^{-3}$ ); they also increased by $78-118 \%$ compared with the concentrations at the background sites $(0.9 \pm 0.1$ (for $\mathrm{HNO}_{3}$ ) to $5.2 \pm 0.3$ (for $\mathrm{NO}_{2}$ ) $\mu \mathrm{g} \mathrm{N} \mathrm{m}{ }^{-3}$; Table 1). Analogous patterns also occurred for all measured $\mathrm{N}_{\mathrm{r}}$ in each region, except for $\mathrm{NH}_{3}$ and $p \mathrm{NH}_{4}^{+}$in the northern region, for which the mean concentrations were 18 and $7 \%$ lower at the urban sites than at the rural sites respectively.

Comparing northern vs. southern regions (Table 1), at urban sites the annual mean concentrations of $\mathrm{NH}_{3}$, $\mathrm{HNO}_{3}$, and $p \mathrm{NH}_{4}^{+}$showed smaller non-significant differences $(-1 \sim 9 \%)$, whereas $\mathrm{NO}_{2}$ and $p \mathrm{NO}_{3}^{-}$showed larger non-significant increases (34 and $76 \%$ respectively) in the north. By contrast, the mean concentrations of all measured $\mathrm{N}_{\mathrm{r}}$ species were significantly $(p<0.05)$ higher (by 40 $104 \%)$ at rural sites in northern region. Similarly, individual concentrations at background sites were 21-71\% higher in the northern than southern region. Averaged across three land use types, the annual mean $\mathrm{N}_{\mathrm{r}}$ concentrations of five $\mathrm{N}_{\mathrm{r}}$ species in the north increased to varying extents (by $84 \%$ for $p \mathrm{NO}_{3}^{-}, 63 \%$ for $p \mathrm{NH}_{4}^{+}, 57 \%$ for $\mathrm{NH}_{3}, 47 \%$ for $\mathrm{NO}_{2}$, and $28 \%$ for $\mathrm{HNO}_{3}$ ) compared with those in the south. The annual concentrations of total $\mathrm{N}_{r}$ (i.e. the sum of five $\mathrm{N}_{r}$ species) decreased in the order urban $>$ rural $>$ background in eastern China as a whole and in the north and south regions; further, the annual total $\mathrm{N}_{\mathrm{r}}$ concentrations at urban and background sites were 17 and $34 \%$ higher $(p>0.05)$ in the north than in the south respectively, whereas those at northern rural sites $\left(31.6 \pm 3.8 \mu \mathrm{g} \mathrm{N} \mathrm{m}^{-3}\right)$ were significantly $(p<0.05)$ higher than the means at southern rural sites $\left(17.0 \pm 1.7 \mu \mathrm{g} \mathrm{N} \mathrm{m}^{-3}\right)$.

The monthly VWM concentrations of $\mathrm{NH}_{4}^{+}-\mathrm{N}, \mathrm{NO}_{3}^{-}-\mathrm{N}$, and TIN (the sum of $\mathrm{NH}_{4}^{+}-\mathrm{N}$ and $\mathrm{NO}_{3}^{-}-\mathrm{N}$ ) were in the ranges 0.01-26.77 (BY and YC), 0.06-28.92 (XS and WJ), and $0.09-50.29 \mathrm{mg} \mathrm{N} \mathrm{L}^{-1}$ (XS and YC) respectively (Table S3, Supplement). In eastern China and in each region, the annual VWM concentrations of $\mathrm{NO}_{3}^{-}-\mathrm{N}$ and TIN showed a declining trend of urban $>$ rural $>$ background, whereas those of $\mathrm{NH}_{4}^{+}-\mathrm{N}$ followed the order rural $\geq$ urban $>$ background (Table 1). Comparing northern and southern regions, the annual concentrations of $\mathrm{NH}_{4}^{+}-\mathrm{N}, \mathrm{NO}_{3}^{-}-\mathrm{N}$, and TIN were comparable at urban and background sites, and were significantly $(p<0.05)$ higher at northern rural sites.

\subsection{Annual variability in concentrations of $N_{r}$ species in air and precipitation}

During the 2011-2015 period the annual mean concentrations of measured $\mathrm{N}_{\mathrm{r}}$ species in air exhibited no significant trends at the 21 selected sites except for $\mathrm{NH}_{3}$ at 4 sites ( $\mathrm{ZZ}$, $\mathrm{DL}, \mathrm{ZMD}, \mathrm{YL}$ ), $\mathrm{HNO}_{3}$ at 3 sites (DL, LSD, BY), $p \mathrm{NH}_{4}^{+}$at 1 site (XS), and total $\mathrm{N}_{\mathrm{r}}$ at 3 sites (ZMD, YL, WJ; Fig. S1a$\mathrm{f}$, Supplement). Similarly, no significant trends were found for the annual VWM concentrations of $\mathrm{NH}_{4}^{+}-\mathrm{N}, \mathrm{NO}_{3}^{-}-\mathrm{N}$, and TIN in precipitation at the 17 selected sites, with the exception of $\mathrm{NO}_{3}^{-}-\mathrm{N}$ at 1 site (SZ; Fig. S2a-c, Supplement).

Figure 2 compares annual average concentrations of all measured $\mathrm{N}_{\mathrm{r}}$ species between the periods 2013-2015 and 2011-2012 for three land use types. In eastern China the mean concentrations of $\mathrm{NH}_{3}$ and $\mathrm{pNH}_{4}^{+}$showed nonsignificant increases (10-38\%) at all land use types except $p \mathrm{NH}_{4}^{+}$at background sites, which showed a small reduction ( $8 \%$; Fig. 2a, d). By contrast, the mean concentrations of remaining $\mathrm{N}_{\mathrm{r}}$ species at three land use types showed smaller and non-significant changes: $-8 \sim 3 \%$ for $\mathrm{NO}_{2}$ (Fig. 2b), $-13 \sim 5 \%$ for $\mathrm{HNO}_{3}$ (Fig. 2c), and $-1 \sim 5 \%$ for $p \mathrm{NO}_{3}^{-}$ (Fig. 2e). The relative changes in the annual total $\mathrm{N}_{\mathrm{r}}$ concentration were also not significant, with the largest increase at rural sites (16\%) and smaller increases at urban (4\%) and background (1\%) sites (Fig. 2f). Separated by regions, annual mean concentrations of five $\mathrm{N}_{\mathrm{r}}$ species at three land use types mostly showed increases (4-57\%) in the north, and reductions $(0.3-21 \%)$ in the south (Fig. 2a-f). The relative changes in individual concentrations at northern rural sites (9\% reduction for $\mathrm{HNO}_{3}$, and 9-52\% increases for the other species) and southern rural sites (4\% increase for $\mathrm{pNH}_{4}^{+}$, and $0.3-21 \%$ reductions for other species) were not significant. The annual total $\mathrm{N}_{\mathrm{r}}$ concentrations showed small rela- 
Table 1. Annual average (standard error) concentrations of various $\mathrm{N}_{\mathrm{r}}$ compounds in air and precipitation at different land use types in eastern China and its northern and southern regions for the 5-year period 2011-2015.

\begin{tabular}{|c|c|c|c|c|c|c|c|c|c|c|}
\hline \multirow[t]{2}{*}{ Region $^{\mathrm{a}}$} & \multirow[t]{2}{*}{$\mathrm{LUT}^{\mathrm{b}}$} & \multicolumn{6}{|c|}{ Ambient conc. $\mu \mathrm{g} \mathrm{N} \mathrm{m}^{-3}$} & \multicolumn{3}{|c|}{ Rainwater conc. $\mathrm{mg} \mathrm{NL}^{-1}$} \\
\hline & & $\mathrm{NH}_{3}$ & $\mathrm{NO}_{2}$ & $\mathrm{HNO}_{3}$ & $p \mathrm{NH}_{4}^{+}$ & $p \mathrm{NO}_{3}^{-}$ & Total $\mathrm{N}_{\mathrm{r}}$ & $\mathrm{NH}_{4}^{+}$ & $\mathrm{NO}_{3}^{-}$ & TIN \\
\hline \multirow[t]{6}{*}{ EC } & urban & 8.5 & 10.2 & 1.6 & 8.2 & 4.0 & 32.6 & 1.6 & 1.9 & 3.5 \\
\hline & $(n=6)$ & (1.4) & (1.0) & $(0.2)$ & (1.8) & $(0.8)$ & (4.1) & $(0.3)$ & $(0.2)$ & $(0.5)$ \\
\hline & rural & 7.2 & 6.0 & 1.2 & 6.7 & 2.8 & 23.9 & 1.7 & 1.4 & 3.1 \\
\hline & $(n=17)$ & $(0.9)$ & $(0.5)$ & (0.1) & (1.1) & $(0.3)$ & (2.7) & $(0.2)$ & $(0.2)$ & $(0.4)$ \\
\hline & $\mathrm{BKD}^{\mathrm{c}}$ & 3.9 & 5.2 & 0.9 & 4.5 & 1.9 & 16.4 & 1.4 & 1.2 & 2.6 \\
\hline & $(n=4)$ & (0.6) & $(0.3)$ & $(0.1)$ & $(0.4)$ & $(0.3)$ & (1.4) & $(0.3)$ & $(0.4)$ & $(0.6)$ \\
\hline \multirow[t]{6}{*}{ NREC } & urban & 8.1 & 11.7 & 1.6 & 8.6 & 5.1 & 35.1 & 2.2 & 2.4 & 4.6 \\
\hline & $(n=3)$ & (2.4) & (1.6) & $(0.3)$ & (2.3) & (1.4) & (7.7) & $(0.4)$ & $(0.2)$ & $(0.4)$ \\
\hline & rural & 9.9 & 7.4 & 1.4 & 9.2 & 3.7 & 31.6 & 2.4 & 2.0 & 4.4 \\
\hline & $(n=8)$ & $(1.2)^{* *}$ & $(0.7)^{*}$ & $(0.1)^{*}$ & $(1.9)^{*}$ & $(0.5)^{*}$ & $(3.8)^{* *}$ & $(0.3)^{* *}$ & $(0.2)^{* *}$ & $(0.4)^{* *}$ \\
\hline & BKD & 4.7 & 5.7 & 1.0 & 5.1 & 2.4 & 18.8 & 1.8 & 1.5 & 3.3 \\
\hline & $(n=2)$ & (0.6) & $(0.3)$ & $(0.1)$ & $(0.2)$ & $(0.3)$ & $(0.1)$ & $(0.2)$ & $(0.3)$ & $(0.1)$ \\
\hline \multirow[t]{6}{*}{ SREC } & urban & 8.9 & 8.7 & 1.6 & 7.9 & 2.9 & 30.1 & 1.1 & 1.5 & 2.6 \\
\hline & $(n=3)$ & (1.8) & (0.6) & $(0.1)$ & (3.1) & $(0.2)$ & (4.5) & $(0.3)$ & $(0.3)$ & $(0.6)$ \\
\hline & rural & 4.9 & 4.6 & 1.0 & 4.5 & 1.9 & 17.0 & 1.1 & 0.9 & 2.0 \\
\hline & $(n=9)$ & (0.6) & (0.6) & $(0.1)$ & (0.6) & $(0.2)$ & (1.7) & $(0.2)$ & $(0.1)$ & $(0.3)$ \\
\hline & BKD & 3.1 & 4.7 & 0.8 & 4.0 & 1.4 & 14.0 & 1.0 & 0.6 & 1.6 \\
\hline & $(n=2)$ & (0.7) & $(0.4)$ & $(0.1)$ & $(0.2)$ & $(0.2)$ & (0.6) & $(0.0)$ & $(0.0)$ & $(0.0)$ \\
\hline
\end{tabular}

a EC: eastern China; NREC: northern region of eastern China; SREC: southern region of eastern China. ${ }^{\mathrm{b}}$ LUT: land use type; $n$ denotes number of monitoring sites. ${ }^{\mathrm{c}}$ BKD: Background. "conc": concentration. * and ** denote significance at the 0.05 and 0.01 probability levels for difference in annual mean $\mathrm{N}_{\mathrm{r}}$ concentrations at a given site type between northern and southern regions respectively.

tive changes (from -1 to $5 \%$ ) across all land use types in the two regions, except at northern rural sites, which exhibited a larger but non-significant increase ( $25 \%$; Fig. 2f). Due to significant interannual variability, longer records are needed to better assess the significance of any concentration changes.

In eastern China, the annual VWM concentrations of $\mathrm{NH}_{4}^{+}-\mathrm{N}, \mathrm{NO}_{3}^{-}-\mathrm{N}$, and TIN showed the largest increase of 26-31\% at background sites, a smaller increase of 4-5\% at rural sites, and a decrease of $2-14 \%$ at urban sites; however, those changes were not significant (Fig. 2g-i). Regionally, their respective concentrations showed increases (3-45\%) in the north and reductions (5-33\%) in the south, except for a small increase (4\%) in $\mathrm{NH}_{4}^{+}-\mathrm{N}$ at background sites.

\subsection{Seasonal variability in concentrations of $N_{r}$ species in air and precipitation}

Figure 3 shows seasonal patterns of $\mathrm{NH}_{3}, \mathrm{NO}_{2}, \mathrm{HNO}_{3}$, $p \mathrm{NH}_{4}^{+}, p \mathrm{NO}_{3}^{-}$, and total $\mathrm{N}_{\mathrm{r}}$ concentrations for three land use types in eastern China and its northern and southern regions, averaged from corresponding measurements at the 27 study sites (details for each site are given in Tables S4-S9 of the Supplement). Average $\mathrm{NH}_{3}$ concentrations at all land use types decreased in the order summer $>$ spring $>$ autumn $>$ winter, and significant seasonal differences generally occurred between summer and winter (Fig. 3a). Conversely, the average $\mathrm{NO}_{2}$ concentration gen- erally showed the highest value in winter and the lowest in summer; differences between seasonal concentrations were sometimes significant at rural sites in the south and background sites, but not at urban sites (Fig. 3b). The seasonal changes in the $\mathrm{HNO}_{3}$ concentration were generally small and not significant for all land use types (Fig. 3c).

The average $p \mathrm{NH}_{4}^{+}$concentration exhibited a nonsignificant seasonal variation across all land use types, except for southern rural sites which showed significantly higher values in winter than in summer (Fig. 3d). The highest $p \mathrm{NH}_{4}^{+}$concentrations mostly occurred in winter. The average $p \mathrm{NO}_{3}^{-}$concentrations at all land use types followed the order winter $>$ spring $\approx$ autumn $>$ summer; the seasonal changes are sometimes significant, except for urban sites in eastern China and its northern region (Fig. 3e). The average concentration of total $\mathrm{N}_{\mathrm{r}}$ usually showed small and non-significant seasonal differences for all land use types (Fig. 3f).

In eastern China and its two regions, the seasonal VWM concentrations of $\mathrm{NH}_{4}^{+}-\mathrm{N}, \mathrm{NO}_{3}^{-}-\mathrm{N}$, and TIN in precipitation at three land use types (averaged from the 27 sites, details in Tables S10-S12 of the Supplement) showed a similar seasonal pattern, with the highest values in winter and the lowest in summer or autumn (Fig. 4a-c). Significant seasonal differences usually occurred between winter and the other three 

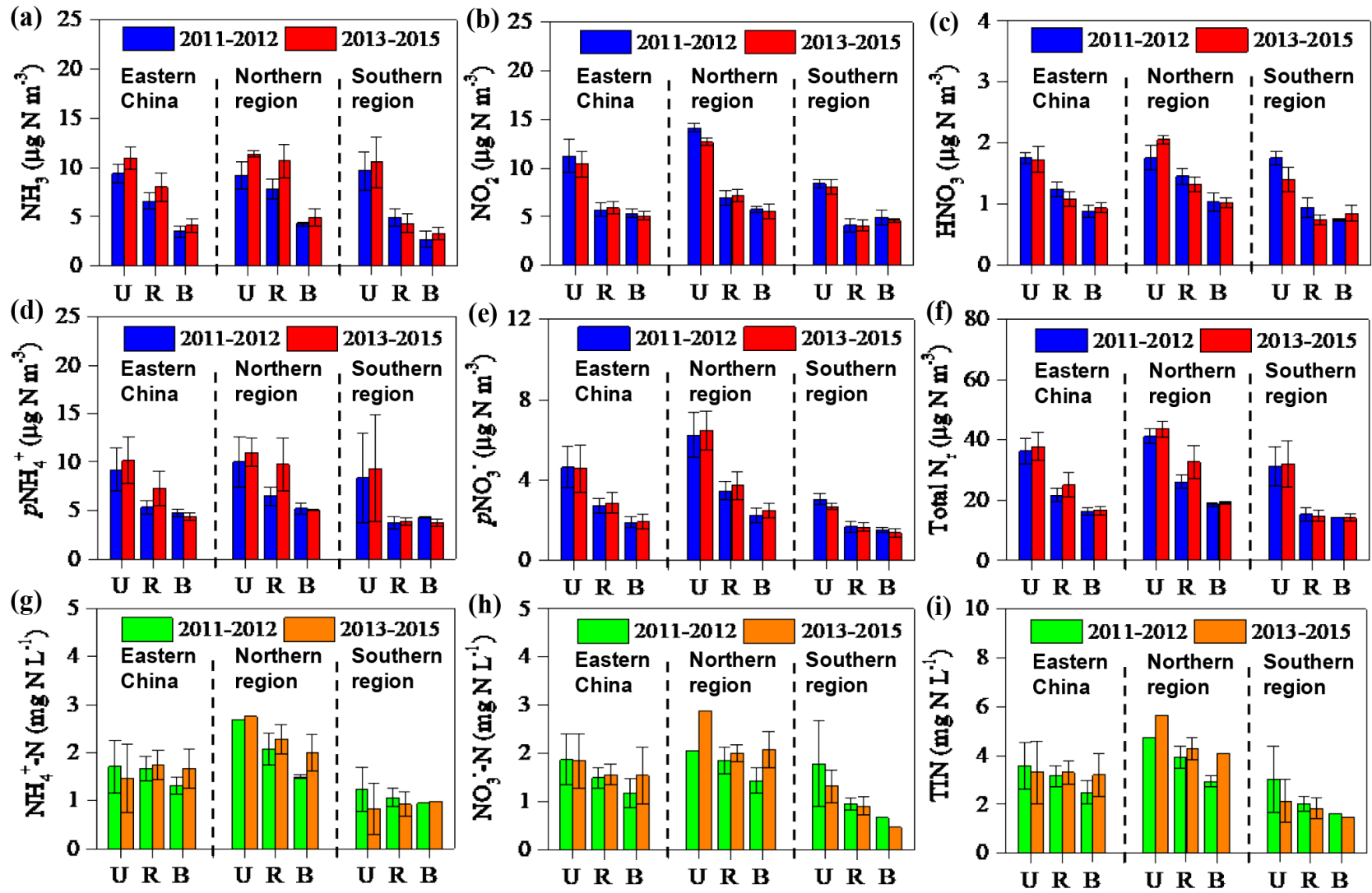

Figure 2. Comparison of annual mean concentrations of (a) $\mathrm{NH}_{3}$, (b) $\mathrm{NO}_{2}$, (c) $\mathrm{HNO}_{3}$, (d) $p \mathrm{NH}_{4}^{+}$, and (e) $p \mathrm{NO}_{3}^{-}$; (f) total $\mathrm{N}_{\mathrm{r}}$, i.e. the sum of all measured $\mathrm{N}_{\mathrm{r}}$ in air; volume-weighted concentrations of $\mathrm{NH}_{4}^{+}(\mathbf{g})$; $\mathrm{NO}_{3}^{-}$(h); total inorganic $\mathrm{N}(\mathrm{TIN})$ : sum of $\mathrm{NH}_{4}^{+}$and $\mathrm{NO}_{3}^{-}$(i), in precipitation between the 2011-2012 period and the 2013-2015 period for different land use types in eastern China and its northern and southern regions. U, R, and B denote urban, rural, and background sites respectively. The number of sites for each land use type in each region can be found in Table S1 in the Supplement. The error bars are the standard errors of means.

seasons at all land use types, except background sites and southern urban sites.

\subsection{Spatial variability in dry and wet/bulk $\mathbf{N}$ deposition of $\mathrm{N}_{\mathrm{r}}$ species}

Dry deposition fluxes of $\mathrm{NH}_{3}, \mathrm{HNO}_{3}, \mathrm{NO}_{2}, p \mathrm{NH}_{4}^{+}$, and $p \mathrm{NO}_{3}^{-}$ranked in the order urban $>$rural $>$background in eastern China and in both southern and northern regions (except for $p \mathrm{NH}_{4}^{+}$in the north; Table 2). Comparing northern and southern regions, at urban sites the mean dry $p \mathrm{NH}_{4}^{+}$deposition was slightly higher $(2 \%)$ in the north, whereas larger enhancements (24-69\%) in the mean fluxes were found in the north for the remaining $\mathrm{N}_{\mathrm{r}}$ species. By contrast, individual fluxes were significantly higher (by 64-138\%) at northern rural sites, except for $\mathrm{HNO}_{3}$, which showed a large nonsignificant increase (58\%). At northern background sites, the mean dry deposition fluxes of $\mathrm{NH}_{3}$ and $\mathrm{NO}_{2}$ were much higher (159\%) and lower (68\%) respectively; however, only small differences in the means were found for $\mathrm{HNO}_{3}(6 \%$ lower in the north), $p \mathrm{NH}_{4}^{+}$(5\% lower), and $p \mathrm{NO}_{3}^{-}$(14\% higher). The spatial pattern of total $\mathrm{N}$ dry deposition flux (the sum of the fluxes of the five $\mathrm{N}_{\mathrm{r}}$ species) by land use types ranked in the same order as individual $\mathrm{N}_{\mathrm{r}}$ species in eastern China. Compared with the southern region, mean total $\mathrm{N}$ fluxes in the north region were significantly higher (by $85 \%$ ) at rural sites, but showed non-significant increases at urban and background sites ( 33 and $38 \%$ respectively).

The wet/bulk deposition fluxes of $\mathrm{NH}_{4}^{+}-\mathrm{N}, \mathrm{NO}_{3}^{-}-\mathrm{N}$, and TIN ranked in the order urban $>$ rural $>$ background in eastern China and in each region (except for $\mathrm{NH}_{4}^{+}-\mathrm{N}$ in the south; Table 2). In addition, their respective fluxes were generally comparable in northern and southern regions.

\subsection{Annual variability in dry and wet/bulk $\mathrm{N}$ deposition}

The annual trends of dry deposition fluxes of individual $\mathrm{N}_{\mathrm{r}}$ species at the 21 selected sites are consistent with trends in their respective ambient concentrations, except for $\mathrm{HNO}_{3}$ at three sites (SZ, LSD, and ZY; Figs. S3a-e and S1a-e, Supplement). A consistent picture is also seen for the total 


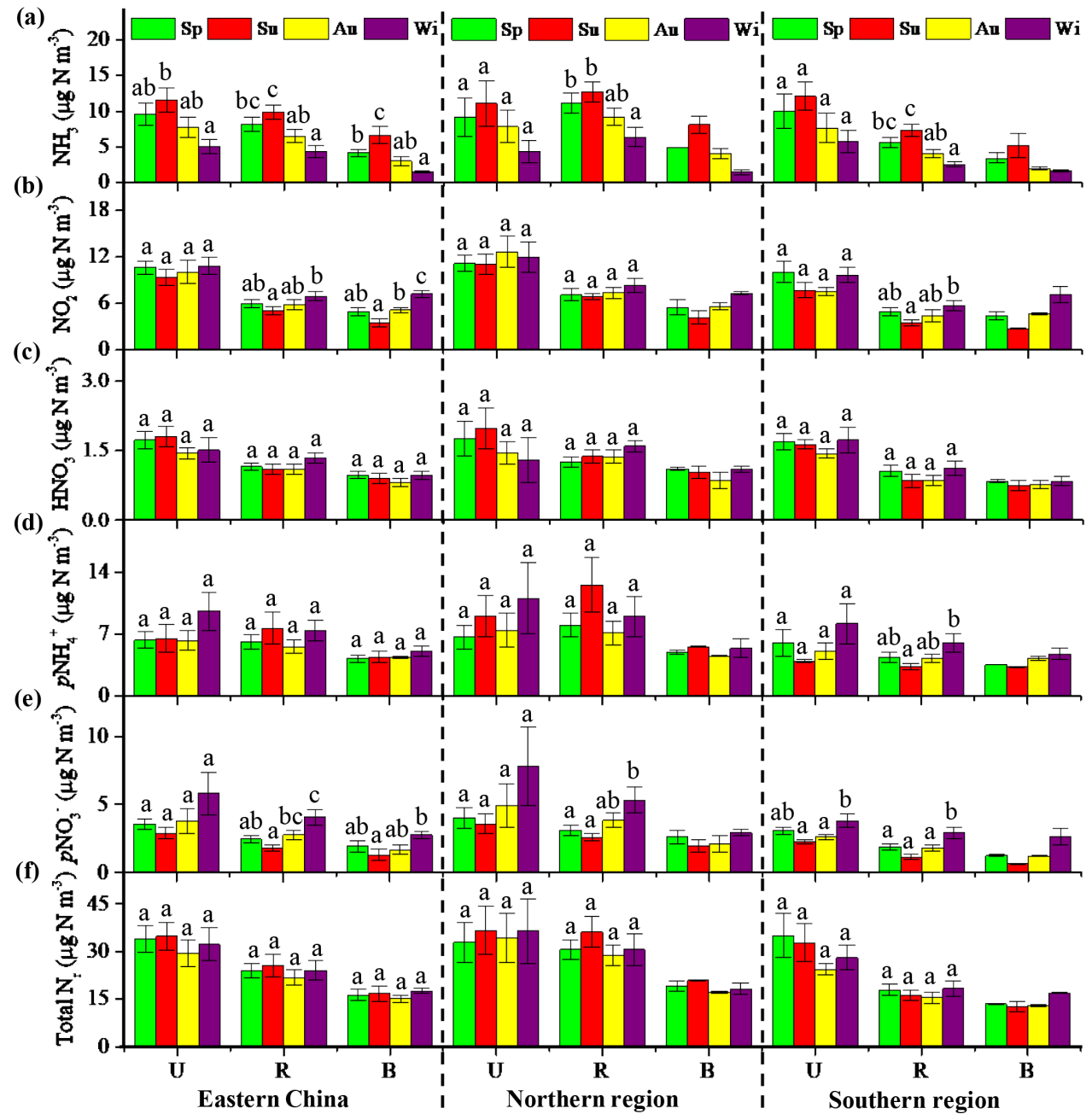

Figure 3. Seasonal mean concentrations averaged over 2011-2015 of (a) $\mathrm{NH}_{3}$, (b) $\mathrm{NO}_{2}$, (c) $\mathrm{HNO}_{3}$, (d) $p \mathrm{NH}_{4}^{+}$, (e) $p \mathrm{NO}_{3}^{-}$, and (f) total $\mathrm{N}_{\mathrm{r}}$, i.e. the sum of all measured $\mathrm{N}_{\mathrm{r}}$ in air, at different land use types in eastern China and its northern and southern regions. Sp, Su, Au, and Wi represent spring, summer, autumn, and winter respectively. U, R, and B denote urban, rural, and background sites respectively. The number of sites for each land use type in each region can be found in Table 1. The error bars are the standard errors of means, and values without same letters on the bars denote significant differences between the seasons $(p<0.05)$.

dry $\mathrm{N}$ deposition fluxes at all but two sites (DL and WJ; Figs. S3f and S1f, Supplement). Similarly, the annual trends of wet/bulk deposition fluxes of $\mathrm{NH}_{4}^{+}-\mathrm{N}, \mathrm{NO}_{3}^{-}-\mathrm{N}$, and $\mathrm{TIN}$ at 17 selected sites are similar to their respective concentrations in precipitation (Fig. S4a-c, Supplement).

In eastern China the annual average dry deposition fluxes of $\mathrm{NH}_{3}, \mathrm{NO}_{2}, \mathrm{HNO}_{3}, p \mathrm{NH}_{4}^{+}$, and $p \mathrm{NO}_{3}^{-}$showed nonsignificant increases $(2-39 \%)$ or reductions $(1-19 \%)$ between the periods 2011-2012 and 2013-2015 at the three land use types (Fig. 5a-e), similar in sign and magnitude to their respective concentrations described earlier. The annual average total $\mathrm{N}$ dry deposition fluxes showed small and nonsignificant increases across the study periods: $2 \%$ at urban sites, $9 \%$ at rural sites, and $7 \%$ at background sites (Fig. 5f). The sign and magnitude of period-to-period changes in dry deposition and ambient concentrations of all measured $\mathrm{N}_{\mathrm{r}}$ species were generally similar between the southern and northern regions.

Wet/bulk deposition fluxes of $\mathrm{NH}_{4}^{+}-\mathrm{N}, \mathrm{NO}_{3}^{-}-\mathrm{N}$, and TIN generally decreased (4-29\%) between 2011-2012 and 2013-2015 at all land use types in eastern China; one exception was $\mathrm{NO}_{3}^{-}-\mathrm{N}$, which exhibited a small increase (3\%) at urban sites (Fig. 5g-i). Similar tendencies were also observed in both northern and southern regions.

\subsection{Seasonal variability in dry and wet/bulk deposition of $\mathrm{N}_{\mathbf{r}}$ species}

Seasonal variations of dry deposition of individual $\mathrm{N}_{\mathrm{r}}$ species at each site are shown in Tables S4-S9 in the Supple- 




Figure 4. Seasonal mean concentrations averaged over 2011-2015 of $\mathrm{NH}_{4}^{+}$(a), $\mathrm{NO}_{3}^{-}$(b), and total inorganic $\mathrm{N}$ (TIN), i.e. the sum of $\mathrm{NH}_{4}^{+}$ and $\mathrm{NO}_{3}^{-}$(c), in precipitation at different land use types in eastern China and its northern and southern regions. Sp, Su, Au, and Wi represent spring, summer, autumn, and winter respectively. U, R, and B denote urban, rural, and background sites respectively. The number of sites for each land use type in each region can be found in Table 1 . The error bars are the standard errors of means, and values without same letters on the bars denote significant differences between the seasons $(p<0.05)$.

Table 2. Annual average (standard error) dry and wet/bulk deposition fluxes $\left(\mathrm{kg} \mathrm{N} \mathrm{ha}^{-1} \mathrm{yr}^{-1}\right)$ of various $\mathrm{N}_{\mathrm{r}}$ compounds at different land use types in eastern China and its northern and southern regions for the 5-year period 2011-2015.

\begin{tabular}{|c|c|c|c|c|c|c|c|c|c|c|}
\hline \multirow[t]{2}{*}{ Region $^{\mathrm{a}}$} & \multirow[t]{2}{*}{$\mathrm{LUT}^{\mathrm{b}}$} & \multicolumn{6}{|c|}{ Dry deposition } & \multicolumn{3}{|c|}{ Wet/bulk deposition } \\
\hline & & $\mathrm{NH}_{3}$ & $\mathrm{NO}_{2}$ & $\mathrm{HNO}_{3}$ & $p \mathrm{NH}_{4}^{+}$ & $p \mathrm{NO}_{3}^{-}$ & Total $\mathrm{N}_{\mathrm{r}}$ & $\mathrm{NH}_{4}^{+}$ & $\mathrm{NO}_{3}^{-}$ & TIN \\
\hline \multirow[t]{6}{*}{$\mathrm{EC}$} & Urban & 12.6 & 4.4 & 7.7 & 4.8 & 2.1 & 31.7 & 12.6 & 15.4 & 28.0 \\
\hline & $(n=6)$ & (1.4) & (1.2) & (1.6) & (1.4) & $(0.5)$ & (4.6) & (1.9) & $(0.7)$ & (2.2) \\
\hline & Rural & 9.1 & 2.9 & 4.6 & 4.0 & 1.5 & 22.1 & 11.9 & 10.2 & 22.1 \\
\hline & $(n=17)$ & $(0.9)$ & $(0.3)$ & (0.6) & $(0.7)$ & $(0.2)$ & (2.3) & (1.0) & $(0.5)$ & (1.4) \\
\hline & $\mathrm{BKD}^{\mathrm{c}}$ & 7.9 & 1.8 & 3.5 & 1.9 & 0.8 & 15.8 & 10.7 & 7.7 & 18.4 \\
\hline & $(n=4)$ & (2.1) & (0.6) & $(0.2)$ & $(0.3)$ & $(0.1)$ & (1.5) & (1.8) & $(0.3)$ & (1.8) \\
\hline \multirow[t]{6}{*}{ NREC } & Urban & 13.9 & 5.2 & 9.4 & 4.9 & 2.7 & 36.2 & 13.9 & 14.1 & 28.0 \\
\hline & $(n=3)$ & (1.9) & (2.5) & (3.0) & (1.9) & (1.0) & (8.2) & (3.5) & $(1.0)$ & (4.4) \\
\hline & Rural & $12.1^{* *}$ & $3.6^{*}$ & 5.7 & $5.7^{*}$ & $2.1^{* *}$ & $29.3^{* *}$ & 12.3 & 10.3 & 22.6 \\
\hline & $(n=8)$ & (1.3) & $(0.4)$ & (1.0) & (1.2) & $(0.3)$ & (3.2) & (1.3) & $(0.7)$ & (1.8) \\
\hline & $\mathrm{BKD}$ & 11.4 & 0.9 & 3.4 & 1.9 & 0.8 & 18.4 & 7.8 & 7.6 & 15.4 \\
\hline & $(n=2)$ & $(0.6)$ & $(0.7)$ & (0.3) & $(0.7)$ & $(0.2)$ & $(0.7)$ & (1.4) & $(0.8)$ & $(0.6)$ \\
\hline \multirow[t]{6}{*}{ SREC } & Urban & 11.2 & 3.6 & 5.9 & 4.8 & 1.6 & 27.2 & 11.4 & 16.6 & 28.0 \\
\hline & $(n=3)$ & (2.0) & $(0.3)$ & (0.6) & (2.6) & $(0.2)$ & (4.0) & (2.0) & $(0.4)$ & (2.1) \\
\hline & Rural & 6.5 & 2.2 & 3.6 & 2.4 & 1.0 & 15.8 & 11.6 & 10.2 & 21.8 \\
\hline & $(n=9)$ & $(0.5)$ & $(0.4)$ & (0.6) & $(0.4)$ & $(0.2)$ & (1.4) & (1.5) & $(0.9)$ & (2.2) \\
\hline & BKD & 4.4 & 2.7 & 3.6 & 2.0 & 0.7 & 13.3 & 13.6 & 7.9 & 21.5 \\
\hline & $(n=2)$ & (1.0) & $(0.2)$ & (0.3) & $(0.1)$ & $(0.1)$ & $(0.7)$ & $(0.1)$ & $(0.1)$ & $(0.1)$ \\
\hline
\end{tabular}

a EC: eastern China; NREC: northern region of eastern China; SREC: southern region of eastern China. ${ }^{\mathrm{b}}$ LUT: land use type; $n$ denotes number of monitoring sites. ${ }^{c}$ BKD: Background. ${ }^{*}$ and ${ }^{* *}$ denote significance at the 0.05 and 0.01 probability levels for difference in annual mean $\mathrm{N}_{\mathrm{r}}$ concentrations at a given site type between northern and southern regions respectively. 



Figure 5. Comparison of dry deposition of (a) $\mathrm{NH}_{3}$, (b) $\mathrm{NO}_{2}$, (c) $\mathrm{HNO}_{3}$, (d) $p \mathrm{NH}_{4}^{+}$, (e) $p \mathrm{NO}_{3}^{-}$, and (f) total $\mathrm{N}_{\mathrm{r}}$ : sum of all measured $\mathrm{N}_{\mathrm{r}}$ in air and wet/bulk deposition of $\mathrm{NH}_{4}^{+}(\mathbf{g})$; $\mathrm{NO}_{3}^{-}(\mathbf{h})$, and total inorganic $\mathrm{N}$ (TIN): sum of $\mathrm{NH}_{4}^{+}$and $\mathrm{NO}_{3}^{-}$(i), in precipitation between the 2011-2012 period and the 2013-2015 period for different land use types in eastern China and its northern and southern regions. U, R, and B denote urban, rural, and background sites respectively. The number of sites for each land use type in each region can be found in Table S1 in the Supplement. The error bars are the standard errors of means.

ment. In eastern China and in each region, dry $\mathrm{NH}_{3}$ deposition fluxes at all land use types followed the order summer $>$ spring $>$ autumn $>$ winter, with the seasonal changes usually significantly different (Fig. 6a). Similarly, the dry $\mathrm{NO}_{2}$ deposition flux was also at its minimum in winter, but its maximum was found in summer at urban and rural sites and in autumn at background site; seasonal differences in most cases were not significant (Fig. 6b). Seasonal patterns of dry $\mathrm{HNO}_{3}$ deposition flux at all land use types were similar to those for dry $\mathrm{NH}_{3}$ deposition fluxes, and the resulting seasonal changes were sometimes significant, except at northern urban sites (Fig. 6c).

Dry $\mathrm{NHH}_{4}^{+}$deposition fluxes peaked in spring or summer at urban and rural sites, but remained at similar levels across the four seasons at background sites; however, no significant seasonal variations were found at any land use types except for rural sites in the north (Fig. 6d). Dry $\mathrm{pNO}_{3}^{-}$deposition fluxes were higher in spring and winter than in summer and autumn at all land use types, and the seasonal changes were sometimes significant at background sites and at southern urban and rural sites (Fig. 6e). Total dry $\mathrm{N}$ deposition fluxes at all land use types showed similar seasonal variations to dry $\mathrm{NH}_{3}$ deposition, with the highest values in summer and the lowest in winter; significant seasonal differences generally were observed between winter and the other three seasons (Fig. 6f).

Wet/bulk deposition fluxes of $\mathrm{NH}_{4}^{+}-\mathrm{N}, \mathrm{NO}_{3}^{-}-\mathrm{N}$, and TIN all showed significant seasonal variation at urban and rural sites, but not at background sites, with the highest values in summer and the lowest in winter (Fig. 7a-c).

\subsection{Spatial-temporal variability in total annual dry and wet/bulk deposition of $\mathrm{N}_{\mathrm{r}}$ species}

In eastern China total annual mean $\mathrm{N}$ deposition (dry plus wet/bulk) fluxes at rural and background sites were comparable (on average $44.3 \pm 3.0$ and $34.3 \pm 0.7 \mathrm{~kg} \mathrm{~N} \mathrm{ha}^{-1} \mathrm{yr}^{-1}$ respectively), but significantly lower than those at urban sites (59.7 $\pm 6.1 \mathrm{~kg} \mathrm{Nha}^{-1} \mathrm{yr}^{-1}$; Table 2, and Fig. S5, Supple- 


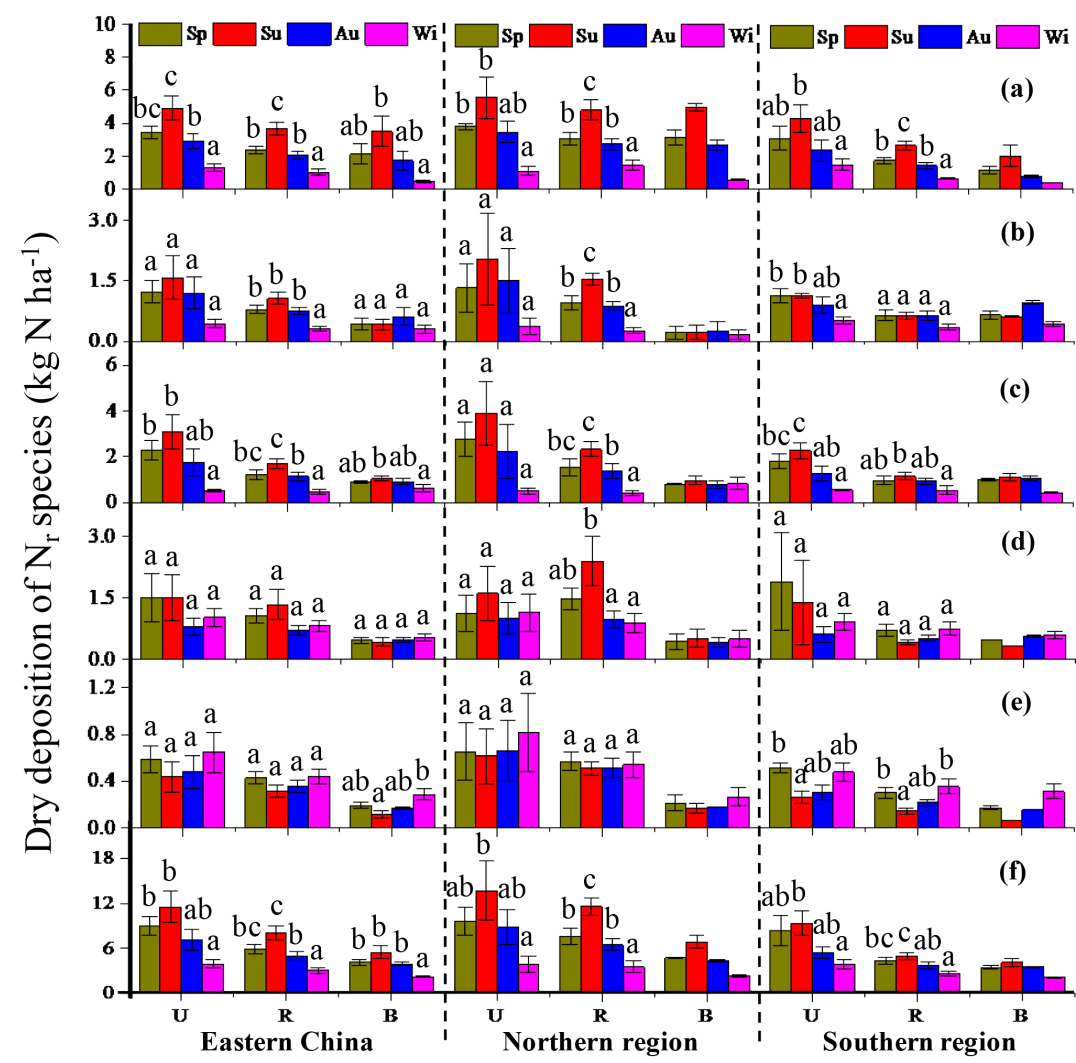

Figure 6. Seasonal mean dry deposition averaged over 2011-2015 of (a) $\mathrm{NH}_{3}$, (b) $\mathrm{NO}_{2}$, (c) $\mathrm{HNO}_{3}$, (d) $p \mathrm{NH}_{4}^{+}$, (e) $p \mathrm{NO}_{3}^{-}$, and (f) total $\mathrm{N}_{\mathrm{r}}$, i.e. the sum of all measured $\mathrm{N}_{\mathrm{r}}$, in air at different land use types in eastern China and its northern and southern regions. Sp, Su, Au, and Wi represent spring, summer, autumn, and winter respectively. U, R, and B denote urban, rural, and background sites respectively. The number of sites for each land use type in each region can be found in Table 2. The error bars are the standard errors of means, and values without same letters on the bars denote significant differences between the seasons $(p<0.05)$.

ment). Similar tendencies for total $\mathrm{N}$ deposition fluxes were observed in the southern region, while in the north a significant difference was only found between urban and background sites (Fig. S5, Supplement). From 2011 to 2015, no significant annual trend was found in the total $\mathrm{N}$ deposition at 16 selected sites (Fig. S6a, Supplement). The total annual mean $\mathrm{N}$ deposition fluxes at three land use types showed small and non-significant reductions (1-5\%) between 20112012 and 2013-2015 (Fig. S6b, Supplement). Regionally, the total fluxes at each land use type were of similar magnitude in the two periods. Also, the ratio of $\mathrm{NH}_{x}$ (wet/bulk $\mathrm{NH}_{4}^{+}-\mathrm{N}$ deposition plus dry deposition of $\mathrm{NH}_{3}$ and particulate $\mathrm{NH}_{4}^{+}$) to $\mathrm{NO}_{y}$ (wet/bulk $\mathrm{NO}_{3}^{-}-\mathrm{N}$ deposition plus dry deposition of $\mathrm{NO}_{2}, \mathrm{HNO}_{3}$ and particulate $\mathrm{NO}_{3}^{-}$) showed a non-significant annual trend across all sites (Fig. 8a). At all land use types, the averaged ratios were slightly higher in the 2013-2015 period than in the 2011-2012 period (Fig. 8b).

\section{Discussion}

\subsection{Comparisons of $\mathrm{NH}_{3}$ and $\mathrm{NO}_{2}$ measurements with satellite data}

Eastern China is a highly industrialized and polluted region, and has been proven to be a hotspot of $\mathrm{N}_{\mathrm{r}}\left(\mathrm{NH}_{3}\right.$ and $\left.\mathrm{NO}_{x}\right)$ emissions and deposition globally (Vet et al., 2014; Kanakidou et al., 2016). The results presented above showed that, in eastern China, annual mean concentrations of measured $\mathrm{N}_{\mathrm{r}}$ species in air and precipitation were generally higher in the north than in the south (Table 1). This is likely due to higher consumption of energy and application of $\mathrm{N}$ fertilizers, along with lower precipitation amounts in the north, previously identified as key factors affecting spatial patterns of $\mathrm{N}$ deposition in China (Liu et al., 2013; Jia et al., 2014; Zhu et al., 2015). Because only 27 sites covering a range of land use types were included in the present study, additional information would be valuable in determining whether the observed spatial patterns adequately represent conditions in eastern China. To address this issue, we use measured $\mathrm{NH}_{3}$ 




Figure 7. Seasonal mean wet/bulk deposition averaged over 2011-2015 of $\mathrm{NH}_{4}^{+}$(a), $\mathrm{NO}_{3}^{-}$(b), and total inorganic $\mathrm{N}$ (TIN), i.e. the sum of $\mathrm{NH}_{4}^{+}$and $\mathrm{NO}_{3}^{-}$(c), in precipitation at different land use types in eastern China and its northern and southern regions. Sp, Su, Au, and Wi represent spring, summer, autumn, and winter respectively. U, R, and B denote urban, rural, and background sites respectively. The number of sites for each land use type in each region can be found in Table 2. The error bars are the standard errors of means, and values without same letters on the bars denote significant differences between the seasons $(p<0.05)$.

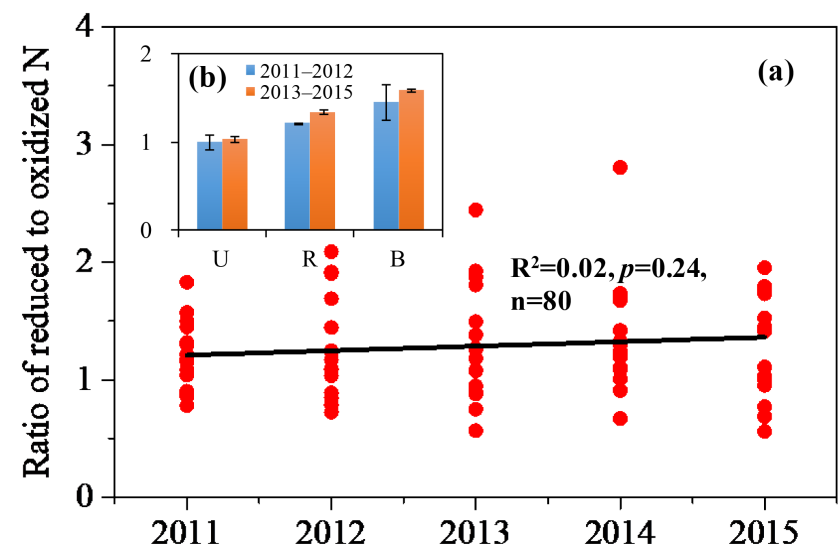

Figure 8. Annual trend of the ratio of $\mathrm{NH}_{x}$ (wet/bulk $\mathrm{NH}_{4}^{+}-\mathrm{N}$ deposition plus dry deposition of $\mathrm{NH}_{3}$ and particulate $\mathrm{NH}_{4}^{+}$) to $\mathrm{NO}_{y}$ (wet/bulk $\mathrm{NO}_{3}^{-}-\mathrm{N}$ deposition plus dry deposition of $\mathrm{NO}_{2}, \mathrm{HNO}_{3}$ and particulate $\mathrm{NO}_{3}^{-}$) across 16 selected sites (a), with a comparison between the 2011-2012 period and the 2013-2015 period for different land use types in eastern China (b). U, R, and B denote urban, rural, and background sites respectively. The number of sites with the same land use type can be found in Fig. S6 in the Supplement.

and $\mathrm{NO}_{2}$ concentrations to evaluate remote sensing techniques for retrieving $\mathrm{NH}_{3}$ and $\mathrm{NO}_{2}$ concentrations. If accurate, these remote sensing techniques are well suited to ascer- tain regional species distributions. $\mathrm{NH}_{3}$ and $\mathrm{NO}_{x}$ are primary emissions with important anthropogenic emissions (Fowler et al., 2013). NO, the main component of emitted $\mathrm{NO}_{x}$, is oxidized in the atmosphere to $\mathrm{NO}_{2} . \mathrm{NO}_{2}$ is further oxidized via daytime or nighttime chemistry to $\mathrm{HNO}_{3}$ (Khoder, 2002). $\mathrm{NH}_{3}$ and $\mathrm{HNO}_{3}$ can react to form fine particle ammonium nitrate (Seinfeld and Pandis, 2006). Thus, spatial patterns of $\mathrm{NH}_{3}$ and $\mathrm{NO}_{2}$ observed from space can be useful indicators of reduced and oxidized $\mathrm{N}_{\mathrm{r}}$ pollution over eastern China.

From satellite observations (Fig. 9a, b), it can be seen that both IASI_NH 3 and OMI_NO ${ }_{2}$ columns show clearly higher values over the northern region of eastern China. Overall, satellite observations and surface measurements for $\mathrm{NH}_{3}$ and $\mathrm{NO}_{2}$ (plotted on the maps of Fig. 9a, b) show a similar spatial pattern. Significant positive correlations were found between IASI_NH 3 column observations and NNDMN_NH measurements $(r=0.72, p<0.001$; Fig. 9c) and between OMI_NO $\mathrm{NO}_{2}$ observations and NNDMN_NO $\mathrm{N}_{2}$ measurements $(r=0.86, p<0.001$; Fig. $9 \mathrm{~d})$ at the 27 surface measurement locations, suggesting that satellite measurements of $\mathrm{NH}_{3}$ and $\mathrm{NO}_{2}$ can be used to capture regional differences in $\mathrm{NH}_{3}$ and $\mathrm{NO}_{2}$ pollution. Looking beyond the surface measurement location, the satellite observations further confirm the existence of greater $\mathrm{N}_{\mathrm{r}}$ pollution in the northern region of eastern China than in the southern region.

To further explore temporal concentration variability, monthly mean satellite $\mathrm{NH}_{3}$ and $\mathrm{NO}_{2}$ columns are compared 
(a)
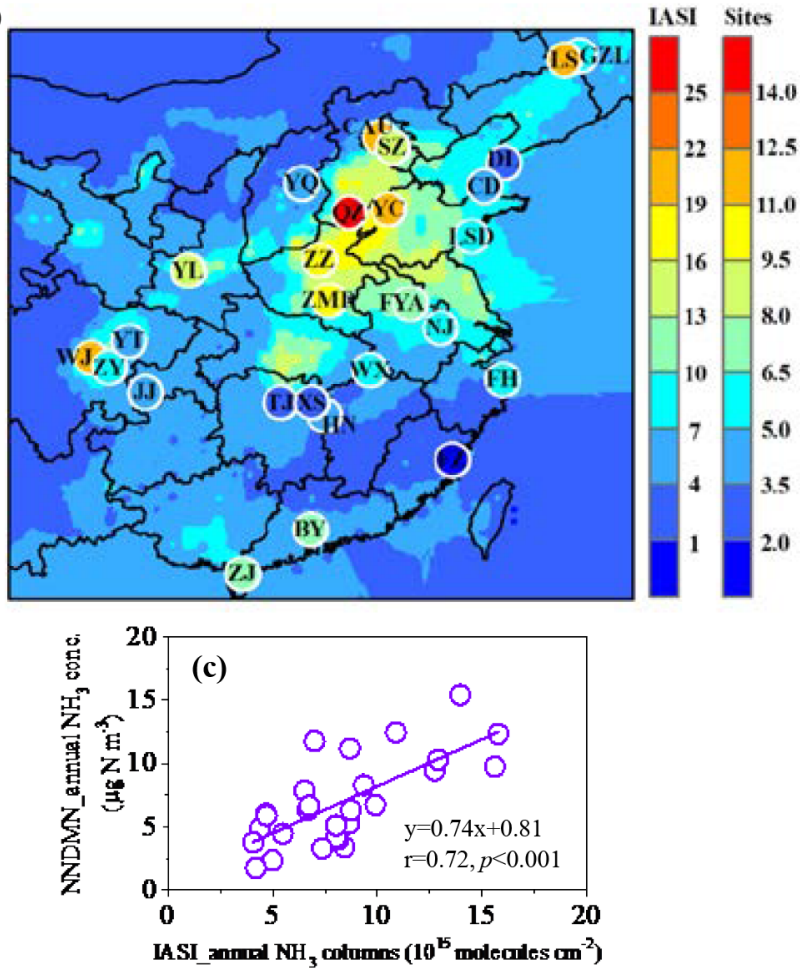

(b)
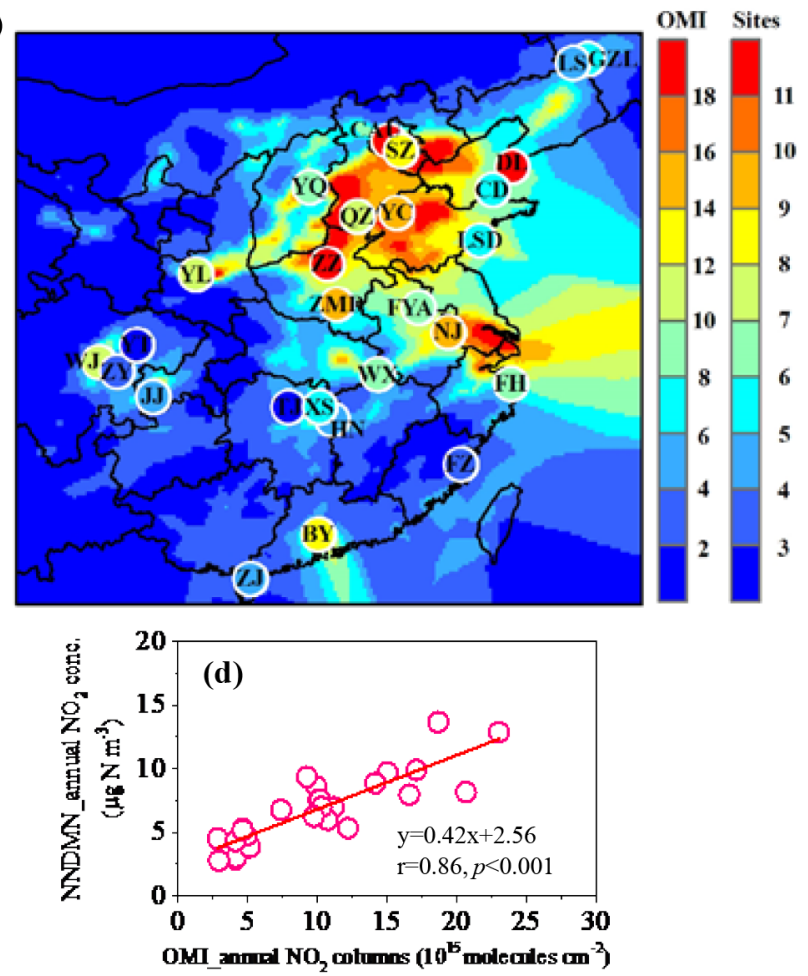

Figure 9. Spatial variation of atmospheric $\mathrm{N}_{\mathrm{r}}$ in eastern China: (a) $\mathrm{NNDMN} \_\mathrm{NH}_{3}$ concentrations vs. IASI_NH $\mathrm{NH}_{3}$ columns; (b) $\mathrm{NNDMN}_{\mathrm{N}} \mathrm{NO}_{2}$ concentrations vs. OMI_NO $\mathrm{N}_{2}$ columns; (c) relationship of NNDMN_NH 3 concentrations vs. IASI_NH $\mathrm{NH}_{3}$ columns; (d) relationship of NNDMN_NO $\mathrm{NO}_{2}$ concentrations vs. OMI_NO $\mathrm{NO}_{2}$ columns.

with monthly mean ground concentrations of $\mathrm{NH}_{3}$ and $\mathrm{NO}_{2}$ (Figs. S7 and S8, Supplement). The linear correlation between satellite columns and surface $\mathrm{NH}_{3}$ concentrations is significant $(p<0.05)$ at the 10 sites $(r=0.32-0.87)$ in the northern region and at 4 sites $(r=0.46-0.84)$ in the southern region (Fig. S7, Supplement), while the linear correlation between satellite columns and surface $\mathrm{NO}_{2}$ concentrations is significant at the 10 sites $(r=0.28-0.68)$ in the northern region and 9 sites $(r=0.36-0.66)$ in the southern region (Fig. S8, Supplement). These results indicate that the OMI_NO $\mathrm{NO}_{2}$ retrieval can well capture the temporal variations of surface $\mathrm{NO}_{2}$ concentrations over eastern China, whereas the IASI_NH $\mathrm{NH}_{3}$ retrievals better capture temporal variability in surface concentrations for the northern region. The weak correlations observed between IASI_NH $\mathrm{NH}_{3}$ observations and surface measurements at 10 of the 14 sites in the southern region (Fig. S7, Supplement) suggest that the IASI_NH $\mathrm{NH}_{3}$ observations need to be improved for investigating temporal variability in $\mathrm{NH}_{3}$ concentration, despite the satellite observation being at a specific time of day, that is, while the surface concentrations integrate across the diurnal cycle of emissions and mixing layer evolution. It should be noted that a direct comparison between surface concentration and satellite column measurements is inevitably affected by many factors, such as changes in boundary layer height, vertical profiles of species, and interferences from cloud and aerosol (Van Damme et al., 2015). Nevertheless, the ratio of satellite column to surface concentration measurements is meaningful as it can provide insight into sensitivity of a satellite retrieval to variation in the concentration of a gas in the surface layer (Meng et al., 2008). To make a more accurate comparison, the vertical profile is recommended to convert the columns to the ground concentrations in future work.

\subsection{Seasonal variations of $N_{r}$ concentration and deposition}

The seasonal concentrations of $\mathrm{N}_{\mathrm{r}}$ species in air and precipitation are dependent on their sources and meteorological conditions. The highest concentrations of $\mathrm{NH}_{3}$ in summer at all land use types (Fig. 3a) are most likely due to enhanced $\mathrm{NH}_{3}$ emissions from natural and fertilized soils, and biological sources such as humans, sewage systems, and organic waste in garbage containers (Chang et al., 2016; Meng et al., 2018). Zhang et al. (2018) showed that $\mathrm{NH}_{3}$ emissions in China show a strong summer peak, with emissions about $50 \%$ higher in summer than spring and autumn. The lowest concentrations of $\mathrm{NH}_{3}$, in winter (Fig. 3a), can be ascribed to low $\mathrm{NH}_{3}$ volatilization under cold conditions, high snow coverage, and less agricultural activity (Cao et al., 2009) with large consumption of $\mathrm{NH}_{3}$ to form $\mathrm{NH}_{4} \mathrm{NO}_{3}$ 
and $\left(\mathrm{NH}_{4}\right)_{2} \mathrm{SO}_{4}$. The lower $\mathrm{NO}_{2}$ concentration in summer (Fig. 3b) might result from higher atmospheric mixing in a deeper boundary layer and a higher rate of oxidation of $\mathrm{NO}_{2}$ to $\mathrm{HNO}_{3}$ by reaction with $\mathrm{OH}$ (Atkins and Lee, 1995), which is more abundant in summer due to greater photochemical activity. Increased $\mathrm{NO}_{2}$ emissions from greater coal combustion for domestic heating (from middle November to middle March) in northern China may also enhance $\mathrm{NO}_{x}$ emissions and subsequent $\mathrm{NO}_{2}$ concentrations in autumn/winter (Zhao et al., 2011).

Particulate $\mathrm{NH}_{4}^{+}$and $\mathrm{NO}_{3}^{-}$are mainly generated via chemical reactions between $\mathrm{NH}_{3}$ and inorganic acids (e.g. $\mathrm{HNO}_{3}, \mathrm{H}_{2} \mathrm{SO}_{4}$ ). We found that concentrations of $p \mathrm{NH}_{4}^{+}$and $p \mathrm{NO}_{3}^{-}$at all land use types usually peaked in winter because low temperature and high emissions of $\mathrm{NO}_{x}$ and $\mathrm{SO}_{2}$ are favourable for formation of $\mathrm{NH}_{4} \mathrm{NO}_{3}$ and $\left(\mathrm{NH}_{4}\right)_{2} \mathrm{SO}_{4}$ aerosols ( $\mathrm{Xu}$ et al., 2016), consistent with higher concentrations of $p \mathrm{NH}_{4}^{+}$and $p \mathrm{NO}_{3}^{-}$. In addition, in winter temperature inversions in combination with stable meteorological conditions (e.g. low wind speed) limit horizontal and vertical exchange of pollutants, and further elevated atmospheric $p \mathrm{NH}_{4}^{+}$and $p \mathrm{NO}_{3}^{-}$levels (F. Liu et al., 2017). In order to identify potential transport of $\mathrm{NO}_{2}, p \mathrm{NH}_{4}^{+}$, and $p \mathrm{NO}_{3}^{-}$ from northern region, we calculated 3-day backward trajectories arriving at five southern sites (Nanjing, Baiyun, Taojing, Ziyang, and Huinong) during January, April, July, and October using the TrajStat. The TrajStat analysis generally showed that the high proportions (overall 10-36\%) of air masses from the north to the south of eastern China occurred in the autumn/winter, suggesting that the transport of $\mathrm{NO}_{2}$, $p \mathrm{NH}_{4}^{+}$, and $\mathrm{NNO}_{3}^{-}$from northern China would result in increases in their respective concentrations in autumn/winter south of the Qinling Mountains-Huaihe River line, except at Ziyang site (Fig. S9, Supplement).

Nitric acid is a secondary pollutant, formed through gasphase reaction of $\mathrm{NO}_{2}$ with the $\mathrm{OH}$ radical, reaction of $\mathrm{NO}_{3}$ with aldehydes or hydrocarbons, or hydrolysis of $\mathrm{N}_{2} \mathrm{O}_{5}$ (Khoder, 2002). Nitric acid concentrations are expected to be further influenced by air temperature, relative humidity, and ambient $\mathrm{NH}_{3}$ concentrations (Allen et al., 1989); fine particle $\mathrm{NH}_{4} \mathrm{NO}_{3}$ formation is favoured at low temperatures and high relative humidities. Due to a lack of information regarding primary formation pathways and influencing factors at our study sites, we cannot offer a definitive explanation for small and differing seasonal patterns of $\mathrm{HNO}_{3}$ concentrations observed at the three land use types (Fig. 3c).

Ammonium- $\mathrm{N}$ and nitrate- $\mathrm{N}$ in precipitation mainly originate from corresponding reduced (e.g. $\mathrm{NH}_{3}, p \mathrm{NH}_{4}^{+}$) and oxidized (e.g. $\mathrm{HNO}_{3}, \mathrm{NO}_{2}, p \mathrm{NO}_{3}^{-}$) $\mathrm{N}$ in air, scavenged respectively by rain and/or snow events (Seinfeld and Pandis, 2006). At all land use types, the seasonal variation of $\mathrm{NH}_{4}^{+}$$\mathrm{N}$ concentration in precipitation was opposite that of reduced $\mathrm{N}$ concentrations (the sum of $\mathrm{NH}_{3}$ and $p \mathrm{NH}_{4}^{+}$; Figs. $4 \mathrm{a}$ and $\mathrm{S} 10 \mathrm{a}$ in the Supplement), whereas a similar seasonal pattern was found between $\mathrm{NO}_{3}^{-}-\mathrm{N}$ and oxidized $\mathrm{N}$ (the sum of
$\mathrm{HNO}_{3}, \mathrm{NO}_{2}$, and $p \mathrm{NO}_{3}^{-}$) concentrations (Figs. $4 \mathrm{~b}$ and $\mathrm{S} 10 \mathrm{~b}$ in the Supplement). Higher precipitation amounts in summer could account for lower $\mathrm{NH}_{4}^{+}-\mathrm{N}$ concentrations in summer (Figs. 4a and S11 in the Supplement) due to a dilution effect (Xu et al., 2015). In contrast, seasonal variations of rainwater $\mathrm{NO}_{3}^{-}-\mathrm{N}$ concentrations were more likely dominated by seasonal changes in oxidized $\mathrm{N}$ concentrations rather than precipitation amount.

The seasonal variation of $\mathrm{NH}_{3}$ dry deposition is generally similar to that of $\mathrm{NH}_{3}$ concentration (Figs. 3a and 6a). Given comparable seasonal mean $V_{\mathrm{d}}$ for $\mathrm{NH}_{3}$ across the four seasons in most cases (Fig. S12a-c, Supplement), the seasonality of $\mathrm{NH}_{3}$ deposition is mainly dominated by changes in ambient $\mathrm{NH}_{3}$ concentrations. Seasonal deposition fluxes of $\mathrm{NO}_{2}$ and $\mathrm{HNO}_{3}$ both differ appreciably (Fig. 6b, c), showing similar variation to seasonality of their respective $V_{\mathrm{d}}$ values (Fig. S12d-i, Supplement). Given weaker seasonal fluctuations of $\mathrm{NO}_{2}$ and $\mathrm{HNO}_{3}$ concentrations, the seasonality of $\mathrm{NO}_{2}$ and $\mathrm{HNO}_{3}$ dry deposition are primarily functions of changes in $V_{\mathrm{d}}$. Similar analyses suggest that seasonal variation of $p \mathrm{NO}_{3}^{-}$dry deposition was mainly caused by differences in seasonal $p \mathrm{NO}_{3}^{-}$concentrations (Figs. 3e and 6e), whereas that of $p \mathrm{NH}_{4}^{+}$dry deposition was primarily driven by seasonal changes in $V_{\mathrm{d}}$ (Figs. $6 \mathrm{c}$ and $\mathrm{S} 12 \mathrm{j}-1$, Supplement).

\subsection{The role of $\mathrm{NH}_{3}$ in mitigation of $\mathrm{N}_{\mathrm{r}}$ air pollution}

The latest pollutant emissions statistics from the Chinese Ministry of Environmental Protection (http://www.zhb.gov. $\left.\mathrm{cn} / \mathrm{gkml} / \mathrm{hbb} / \mathrm{qt} / 201507 / \mathrm{t} 20150722 \_307020 . \mathrm{htm}\right)$ showed that total annual emissions of $\mathrm{SO}_{2}$ and $\mathrm{NO}_{x}$ were respectively reduced by 12.9 and $8.6 \%$ in 2014 (approximately 9.9 and $6.3 \mathrm{Tg} \mathrm{Syr}^{-1}$ respectively), compared with those in 2010 (approximately 11.3 and $6.9 \mathrm{Tg} \mathrm{S} \mathrm{yr}^{-1}$ respectively). This suggests that the goal set for the 12th FYP period was fulfilled ahead of time. Our field measurements demonstrate that annual mean concentrations of each $\mathrm{N}_{\mathrm{r}}$ species and total $\mathrm{N}_{\mathrm{r}}$ did not show significant decreasing trends at most sites during the 2011-2015 period (Fig. S1a-f, Supplement). Furthermore, annual mean total $\mathrm{N}_{\mathrm{r}}$ concentrations showed non-significant increases $(1-16 \%)$ at three land use types during the 2013-2015 period compared with 2011-2012 (Fig. 2f). These results together suggest that $\mathrm{N}_{\mathrm{r}}$ pollution may be not effectively mitigated in eastern China during the 12th FYP, likely due to the absence of $\mathrm{NH}_{3}$ regulations, despite enforcement of a "Zero Increase Action Plan" by the Ministry of Agriculture for national fertilizer use (Liu et al., 2016).

Ammonia is the primary alkaline gas in the atmosphere. It plays an important role in formation of $\left(\mathrm{NH}_{4}\right)_{2} \mathrm{SO}_{4}$ and $\mathrm{NH}_{4} \mathrm{NO}_{3}$ aerosols (Seinfeld and Pandis, 2006). These secondary inorganic aerosols account for 40-57\% of the $\mathrm{PM}_{2.5}$ concentrations in eastern China (Yang et al., 2011; Huang et al., 2014). Based on monthly mean molar concentrations, there were significant positive linear correlations between 
$\mathrm{NH}_{3}$ and $p \mathrm{NH}_{4}^{+}, \mathrm{NO}_{2}$ and $p \mathrm{NO}_{3}^{-}, \mathrm{SO}_{2}$ and $p \mathrm{SO}_{4}^{2-}, p \mathrm{NH}_{4}^{+}$ and $p \mathrm{NO}_{3}^{-}$, and $p \mathrm{NH}_{4}^{+}$and $p \mathrm{SO}_{4}^{2-}$ at all land use land types except for a non-significant relationship of $\mathrm{NH}_{3}$ with $p \mathrm{NH}_{4}^{+}$at background sites (Fig. 10a-e). These results suggest that the precursor gases are responsible for the formation of secondary inorganic ions (i.e. $p \mathrm{NH}_{4}^{+}, p \mathrm{NO}_{3}^{-}$, and $p \mathrm{SO}_{4}^{2-}$ ) locally at urban and rural sites, while secondary inorganic ions at background sites likely originated from long-distance transport. The ratio of concentrations of $\mathrm{NH}_{3}$ to $\mathrm{NH}_{x}\left(\mathrm{NH}_{3}\right.$ plus $\left.p \mathrm{NH}_{4}^{+}\right)$at urban $(0.53 \pm 0.15)$ and rural $(0.52 \pm 0.16)$ sites exceeded values at background $(0.43 \pm 0.16)$ sites. According to Walker et al. (2004), a value greater than 0.5 indicates that $\mathrm{NH}_{x}$ is more likely to be from local sources as opposed to long-range transport.

It is known that $\mathrm{NH}_{3}$ in the atmosphere is preferentially neutralized by $\mathrm{H}_{2} \mathrm{SO}_{4}$ to form $\left(\mathrm{NH}_{4}\right)_{2} \mathrm{SO}_{4}$ and/or $\mathrm{NH}_{4} \mathrm{HSO}_{4}$, with any remainder available for potential reaction with $\mathrm{HNO}_{3}$ to form $\mathrm{NH}_{4} \mathrm{NO}_{3}$. At urban and rural sites, monthly mean $p \mathrm{NH}_{4}^{+}$concentrations significantly positively correlated with the sum of $p 2 \mathrm{SO}_{4}^{2-}$ and $p \mathrm{NO}_{3}^{-}$concentrations (Fig. 10f). However, the slopes of regression equations between them were both smaller than unity $(0.35$ and 0.46 at urban and rural sites respectively), indicating an incomplete neutralization of acidic species $\left(\mathrm{HNO}_{3}\right.$ and $\left.\mathrm{H}_{2} \mathrm{SO}_{4}\right)$ by $\mathrm{NH}_{3}$ at urban and rural sites. In other words, $\mathrm{NH}_{3}$ is a factor limiting the formation of secondary inorganic ions. A model simulation by Wang et al. (2011) found that, without $\mathrm{NH}_{3}$ emission controls, $\mathrm{NO}_{3}^{-}$in $\mathrm{PM}_{2.5}$ will be enhanced by $10 \%$ in 2030 compared with 2005 in China, despite improved $\mathrm{NO}_{x}$ emissions controls. As reported by Zhang et al. (2017), total $\mathrm{NH}_{3}$ emissions in China increased from $12.1 \mathrm{Tg} \mathrm{N} \mathrm{yr}^{-1}$ in 2000 to $15.6 \mathrm{Tg} \mathrm{N} \mathrm{yr}^{-1}$ in 2015 at an annual rate of $1.9 \%$. In contrast, total emissions of $\mathrm{NO}_{x}$ and $\mathrm{SO}_{2}$ have decreased or stabilized in recent years, and were estimated to be 8.4 and 12.5 $\mathrm{Tg} \mathrm{S} \mathrm{yr}^{-1}$ in 2014 respectively (Xia et al., 2016). Based on these factors, implementation of $\mathrm{NH}_{3}$ control strategies, together with more stringent $\mathrm{NO}_{x}$ and $\mathrm{SO}_{2}$ emission controls, should be considered to mitigate atmospheric $\mathrm{N}_{\mathrm{r}}$ pollution.

\subsection{The role of $\mathrm{NH}_{3}$ emissions in control of $\mathrm{N}$ deposition}

The present results showed that total dry $\mathrm{N}$ deposition fluxes at three land use types were higher in the northern region of eastern China than in the southern region (Table 1), mainly due to higher $\mathrm{NH}_{3}$ dry deposition resulting from higher $\mathrm{NH}_{3}$ concentrations in the north. This is especially true for northern rural sites (Table 1), mostly located in the North China Plain (NCP; see details in Xu et al., 2015). The NCP (that is, the plain areas in Beijing, Tianjin, Hebei, Henan, and Shandong provinces), a highly populated region with intensive agricultural production, contributes $30-40 \%$ of the total annual $\mathrm{NH}_{3}$ emissions in China (Huang et al., 2012). In addition, higher $\mathrm{NH}_{3}$ concentration is also likely due to the higher $\mathrm{NH}_{3}$ volatilization in calcareous soils than that in the acidic red soil, as mentioned in Sect. 2.1. Total annual $\mathrm{NH}_{3}$ emissions in northern region increased from $4.3 \mathrm{Tg} \mathrm{N} \mathrm{yr}^{-1}$ in 2011 to $4.7 \mathrm{Tg} \mathrm{N} \mathrm{yr}^{-1}$ in 2015 at an annual rate of $1.8 \%$. In contrast, the emissions of $\mathrm{NO}_{x}$ and $\mathrm{SO}_{2}$ averaged 2.8 and $3.7 \mathrm{Tg} \mathrm{S} \mathrm{yr}^{-1}$ during 2011-2015, and decreased at annual rates of 6.8 and $5.7 \%$ respectively (details of the emissions will be illustrated in Sect. 4.5). Such reductions may enhance free $\mathrm{NH}_{3}$ in the atmosphere. However, according to a modelling study by Han et al. (2017), the influence of removing anthropogenic $\mathrm{SO}_{2}$ emissions on dry $\mathrm{N}$ deposition fluxes during 2010-2014 was quite weak, with the change within $\sim-0.5$ to $\sim 0.5\left(\mathrm{~kg} \mathrm{Nha}^{-1} \mathrm{yr}^{-1}\right)$ over most regions in China. Thus, we anticipate that reducing $\mathrm{NH}_{3}$ emissions can effectively control $\mathrm{N}$ deposition.

To further examine contributions of $\mathrm{NH}_{3}$ emissions to total (wet plus dry) $\mathrm{N}$ deposition at each site and over eastern China, we conducted model sensitivity tests using the nested GEOS-Chem atmospheric chemistry model driven by the GEOS- 5 assimilated meteorological fields at a horizontal resolution of $1 / 2^{\circ} \times 2 / 3^{\circ}$. The model used anthropogenic emissions from the Multi-Resolution Emission Inventory of China (MEIC, http://meicmodel.org) for the year 2010, except for $\mathrm{NH}_{3}$ emissions that are taken from the Regional Emission in Asia (REAS-v2) inventory (Kurokawa et al., 2013), with an improved seasonality derived by Zhao et al. (2015). The total $\mathrm{NH}_{3}$ and $\mathrm{NO}_{x}$ emissions from each source over eastern China and its contribution to total emissions in China are presented in Table S13 in the Supplement. The $\mathrm{NH}_{3}$ and $\mathrm{NO}_{x}$ emissions over eastern China are 11.6 and $8.5 \mathrm{Tg} \mathrm{N} \mathrm{yr}^{-1}$ in 2010, which, respectively account for 90 and $89 \%$ of their total emissions over China. Agricultural sources including fertilizer use and livestock comprise most of the $\mathrm{NH}_{3}$ emissions while fuel combustion activities including industry, power plant, and transportation contribute most of the $\mathrm{NO}_{x}$ emissions and small amounts of $\mathrm{NH}_{3}$ emissions. Both $\mathrm{NH}_{3}$ and $\mathrm{NO}_{x}$ have natural sources (including lightning, biomass burning, and soil emissions), but they are negligible compared to anthropogenic emissions over eastern China. Details of the model emissions and mechanisms have been described elsewhere (Zhao et al., 2017; Xu et al., 2018).

We evaluate the model simulations by comparison with measured bulk (both $\mathrm{NH}_{4}^{+}-\mathrm{N}$ and $\mathrm{NO}_{3}^{-}-\mathrm{N}$ ) fluxes. The model biases for bulk $\mathrm{NH}_{4}^{+}-\mathrm{N}$ and $\mathrm{NO}_{3}^{-}-\mathrm{N}$ deposition were 23 and $-23 \%$ respectively (Fig. S13, Supplement). These biases are reasonable, given uncertainties in $\mathrm{N}_{\mathrm{r}}$ emissions and predictions of meteorology. Given that model evaluation is not central to this work, we presented the details in Sect. S2 in the Supplement. As shown in Fig. 11, fertilizer use is the dominant source of total $\mathrm{N}$ deposition at all sites, with contributions between 16 and $50 \%$. Also, over eastern China the largest contribution was from fertilizer use $(36 \%)$ relative to livestock $(10 \%)$, industry $(14 \%)$, power plant $(11 \%)$, transportation $(9 \%)$, and other sources $(20 \%$, the sum of contributions from human waste, residential activities, soil, light- 

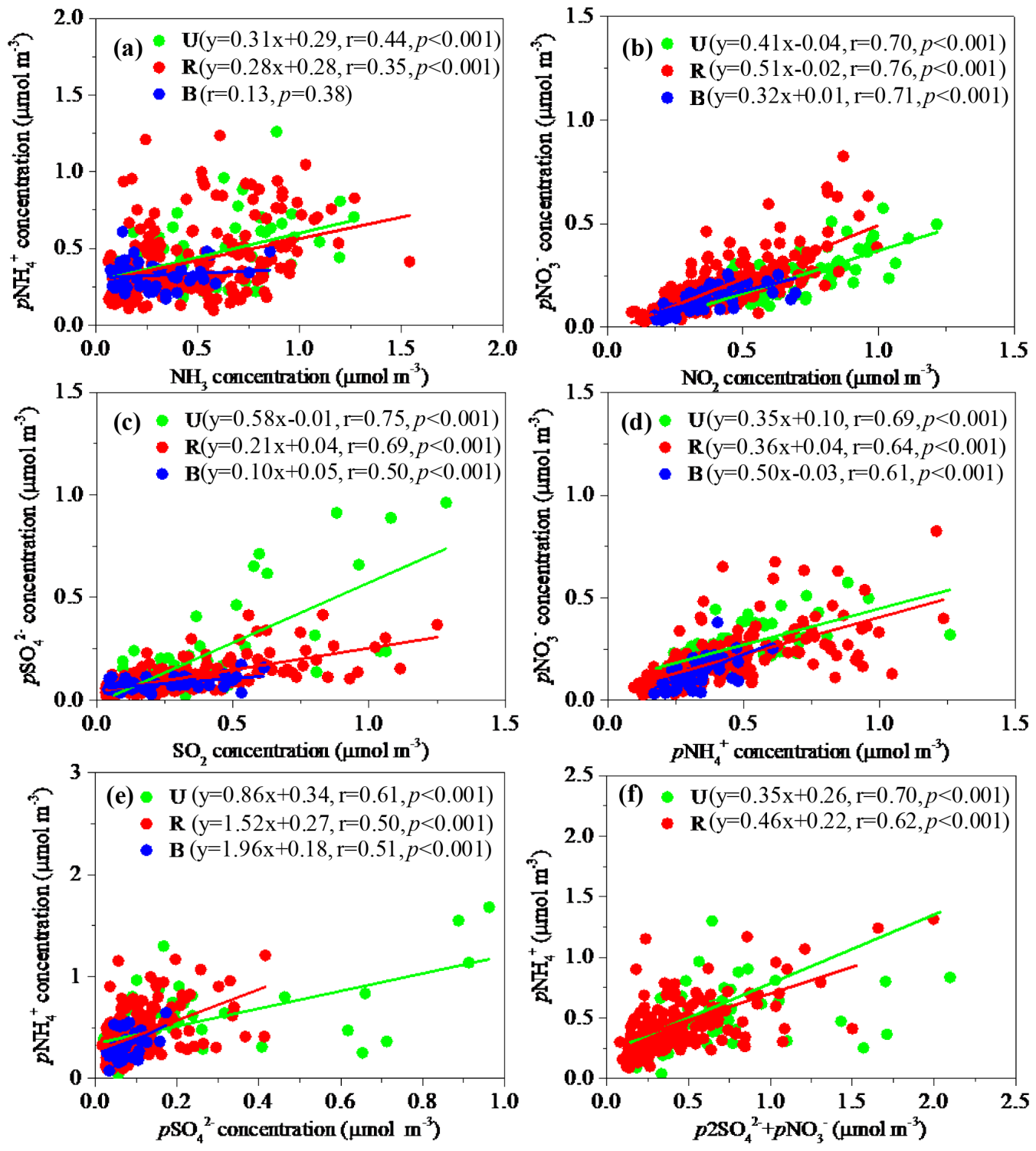

Figure 10. Correlations of monthly mean molar concentrations of (a) $p \mathrm{NH}_{4}^{+}$vs. $\mathrm{NH}_{3}$, (b) $p \mathrm{NO}_{3}^{-}$vs. $\mathrm{NO}_{2}$, (c) $p \mathrm{SO}_{4}^{2-}$ vs. $\mathrm{SO}_{2}$, (d) $p \mathrm{NO}_{3}^{-}$ vs. $p \mathrm{NH}_{4}^{+}$, (e) $p \mathrm{NH}_{4}^{+}$vs. $p \mathrm{SO}_{4}^{2-}$, (f) $p \mathrm{NH}_{4}^{+}$vs. $\left(p 2 \mathrm{SO}_{4}^{2-}+p \mathrm{NO}_{3}^{-}\right)$at three land use types in eastern China. The number of sites with the same land use type in each region can be found in Table 1 .

ing, and biomass burning). These results indicate that reducing $\mathrm{NH}_{3}$ emissions by use of appropriate fertilization patterns (e.g. 4R technologies: right amount, right time, right form, and right application technique; Ju et al., 2009) should be a priority in curbing $\mathrm{N}$ deposition in eastern China. This conclusion to some extent is supported by increased ratios of reduced to oxidized $\mathrm{N}$ in the total deposition at three land use types (Fig. 8b), as the major anthropogenic source of reduced $\mathrm{N}$ is mainly affected by $\mathrm{NH}_{3}$ volatilized from animal excrement and the application of nitrogenous fertilizers in agriculture. Absence of $\mathrm{NH}_{3}$ emission controls may be the main reason for a small and non-significant change in the total $\mathrm{N}$ de- position between 2011-2012 and 2013-2015 (Fig. S6, Supplement), despite enforcement of stringent emission controls on $\mathrm{NO}_{x}$ and $\mathrm{SO}_{2}$. To test the importance of future $\mathrm{NH}_{3}$ emission control strategies, we conducted separate model simulations which reduced $\mathrm{NH}_{3}$ emissions from fertilizer use by $20 \%$. The results show that a $20 \%$ reduction in fertilizer $\mathrm{NH}_{3}$ emissions can lead to $7.4 \%$ decrease in total $\mathrm{N}$ deposition over eastern China.

\subsection{Deposition response to emission change}

Similar to $\mathrm{N}_{\mathrm{r}}$ concentrations, there were no significant decreasing trends in dry and bulk deposition of total $\mathrm{N}$ or of in- 




Figure 11. Fractional contributions to total $\mathrm{N}$ deposition from emission sectors (i.e. fertilizer use, livestock, industry, power plant, transportation, and others including emissions from human waste, residential activities, soil, lighting, and biomass burning) at the 27 sites and over eastern China.

dividual $\mathrm{N}_{\mathrm{r}}$ species at almost all study sites (Figs. $\mathrm{S} 3$ and $\mathrm{S} 4$, Supplement). In addition, we found that changes in annual mean deposition fluxes of various $\mathrm{N}_{\mathrm{r}}$ species are fairly small between the 2013-2015 and 2011-2012 periods (Fig. 5). These results suggest that current emission controls did not effectively reduce $\mathrm{N}$ deposition in eastern China.

To further assess the relationship between emission and deposition change, we considered the emissions of $\mathrm{SO}_{2}$, $\mathrm{NO}_{x}$, and $\mathrm{NH}_{3}$ affecting the 16 study sites with continuous and simultaneous dry and bulk deposition measurements (Fig. S6 and Table S1, Supplement). The regional $\mathrm{NH}_{3}$ emission data for 2011-2015 were derived from Zhang et al. (2017), while $\mathrm{SO}_{2}$ and $\mathrm{NO}_{x}$ emission data for 2011-2014 were derived from Xia et al. (2016; emission data for the year 2015 were provided by Yu Zhao, and were unpublished). We compared these annual data with annual mean deposition values from the 16 sites. It should be noted that such assessment is subject to some uncertainty, as emission data were estimated based on the areas belonging to eastern China.

A clear decreasing trend in $\mathrm{SO}_{2}$ and $\mathrm{NO}_{x}$ emissions was observed, with reductions of 32 and $25 \%$ in 2015 compared to 2011 respectively (Fig. 12a, b). This reduction is directly related to the widespread use of selective catalytic reduction and flue gas de-sulfurization on power plants and industries (Van der A et al., 2017), and to a lesser extent to the introduction of new emission standards for cars (Liu et al., 2016). In contrast, $\mathrm{NH}_{3}$ emissions generally showed a gradual increasing trend between 2011 and 2015 (Fig. 12c), as control strategies have not yet been enacted and implemented for $\mathrm{NH}_{3}$ emissions in China.

Regarding $\mathrm{N}$ deposition, a non-significant increasing trend was found for $\mathrm{NH}_{x}$ (slope $=0.36 \mathrm{~kg} \mathrm{Nha}^{-1} \mathrm{yr}^{-1}$ ) between the 2011 and 2015 period, whereas $\mathrm{NO}_{y}$ deposition exhibited a non-significant decreasing trend (slope $=0.54 \mathrm{~kg} \mathrm{Nha}^{-1} \mathrm{yr}^{-1}$ ). Also, there were nonsignificant linear correlations between $\mathrm{NH}_{x}$ deposition and $\mathrm{NH}_{3}$ emissions and between $\mathrm{NO}_{y}$ deposition and $\mathrm{NO}_{x}$ emissions. This is not surprising given that atmospheric chemistry is complex and often behaves non-linearly (Fowler et al., 2007; Fagerli and Aas, 2008). Interactions between the different pollutants, precipitation variability, and changes in the relative amounts and lifetimes of the chemical species, and in gas-particle partitioning all may contribute to the lack of correlation between emission and deposition trends. Non-linearities between emission and deposition change have been described also elsewhere (Aguillaume et al., 


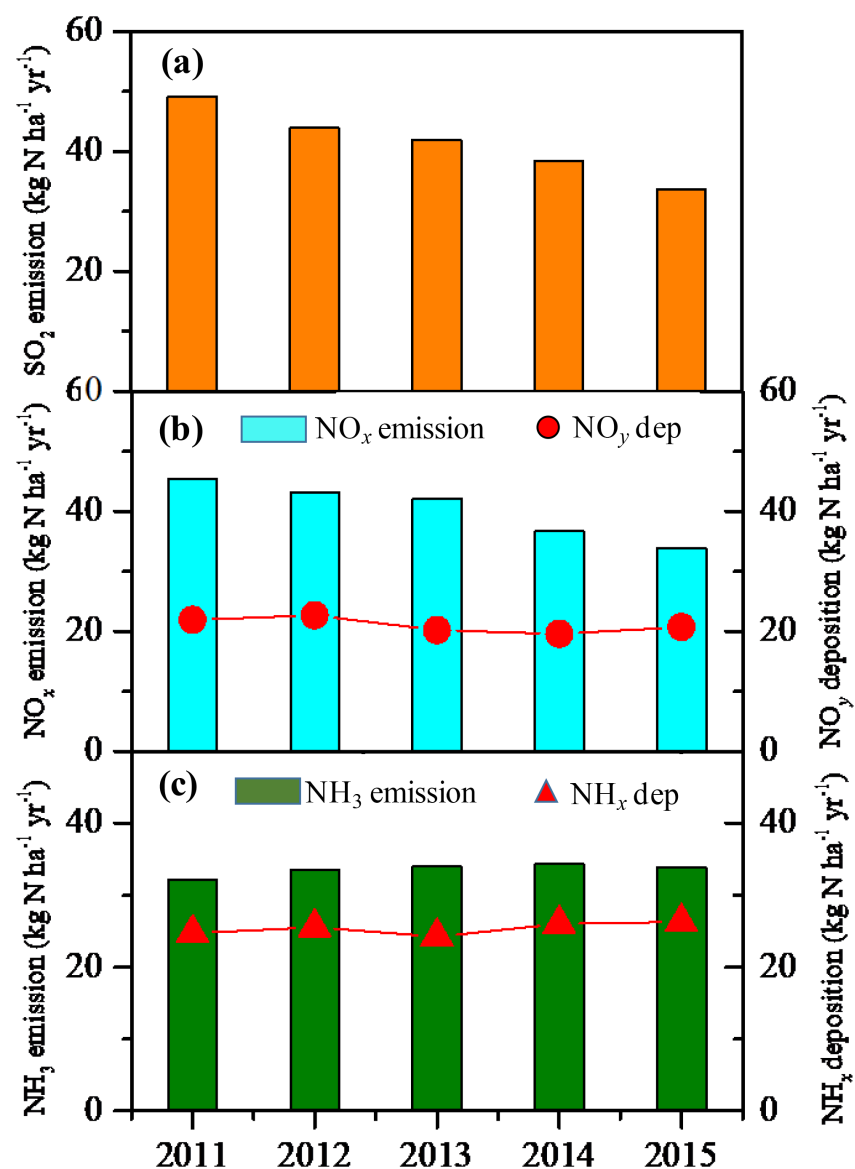

Figure 12. Emissions of $\mathrm{SO}_{2}(\mathbf{a}), \mathrm{NO}_{x}(\mathbf{b})$, and $\mathrm{NH}_{3}$ (c) obtained as average data from the areas belonging to eastern China, compared with deposition (dep) values in the same periods (mean values from the 16 sites showing in Fig. S6 and Table S1 in the Supplement, 5-year averages).

2016; Karlsson et al., 2011). Deposition in eastern China is also influenced by emissions from outside the region, further degrading any expected correlation with local emissions.

\subsection{Uncertainties and limitations}

The present study examined annual trends of concentrations of $\mathrm{N}_{\mathrm{r}}$ species in air and precipitation as well as dry and bulk $\mathrm{N}$ deposition based on Kendall tests and only five annual data values (2011-2015). Although the test can use as few as four data points, indications of statistically significant trends for data sets are unlikely to be truly representative of the trends that are actually occurring due to in the short duration of the measurement data set. Longer time series (e.g. more than 10 years) will likely allow detection of more significant time trends in future work. Another uncertainty may arise from the fact that we used fixed monthly mean dry deposition velocities of gaseous and particulate $\mathrm{N}_{\mathrm{r}}$ species for the same months from June 2013 to December 2015. Nevertheless, the uncertainty in the $V_{\mathrm{d}}$ value did not largely af- fect the deposition trend, as the annual trend in dry deposition of $\mathrm{N}_{\mathrm{r}}$ species is more likely driven by changes in ambient $\mathrm{N}_{\mathrm{r}}$ concentrations than by changing deposition velocities, as evident from fairly low standard deviations of annual mean $V_{\mathrm{d}}$ of $\mathrm{N}_{\mathrm{r}}$ species at our selected 27 sites between 2008 and $2012\left(\sim 0.029\right.$ for $\mathrm{NH}_{3}, \sim 0.005$ for $\mathrm{NO}_{2}, \sim 0.054$ for $\mathrm{HNO}_{3}$, and $\sim 0.019$ for both $p \mathrm{NH}_{4}^{+}$and $p \mathrm{NO}_{3}^{-}$; data were extracted from Zhao et al., 2017).

In addition, we did not account for inter-annual changes in meteorology, which also strongly influences atmospheric $\mathrm{N}_{\mathrm{r}}$ levels and $\mathrm{N}$ deposition (Xu et al., 2015, 2017). For example, air concentrations of $\mathrm{NO}_{2}, \mathrm{NH}_{3}, p \mathrm{NH}_{4}^{+}$, and $p \mathrm{NO}_{3}^{-}$ tend to increase under the relatively stagnant conditions prior to a cold front's arrival and decrease substantially after the cold front brings precipitation and strong winds into the region (Xu et al., 2017). On the inter-annual timescale, the frequency of cold front passage may be affected by largescale circulation patterns such as the position of the Siberian High for eastern China (Jia et al., 2015). For example, a large inter-annual variation in precipitation amount was observed at the selected 16 sites during 2011-2015 (Fig. S14, Supplement), which partially lead to inter-annual changes in wet/bulk $\mathrm{N}$ deposition. However, given that in situ measurements of other meteorological variables (e.g. air temperature, relative humidity, air pressure, wind speed and direction) are not available, and that GEOS-5 assimilated meteorological fields were updated after May 2013, an evaluation of the effect of meteorology on $\mathrm{N}_{\mathrm{r}}$ concentration and deposition is recommended for future work.

Uncertainties also exist in the source attribution calculated with the GEOS-Chem simulations, since results largely depend on the emission inventories fed to the model. Zhao et al. (2017) pointed out that uncertainties in current $\mathrm{NH}_{3}$ emissions inventories (e.g. large range of emission values in current studies and absence of bi-directional $\mathrm{NH}_{3}$ exchange between the land and atmosphere) may influence nitrogen deposition simulation in China. Future work based on improved $\mathrm{NH}_{3}$ emission inventories (e.g. Zhang et al., 2018) and including bidirectional ammonia exchange with the surface is essential to better examine source attribution of $\mathrm{N}$ deposition in China.

\section{Conclusion}

We have characterized spatial and temporal (annual and seasonal) variations in concentrations and deposition of major $\mathrm{N}_{\mathrm{r}}$ species in air $\left(\mathrm{NH}_{3}, \mathrm{NO}_{2}, \mathrm{HNO}_{3}, p \mathrm{NH}_{4}^{+}\right.$, and $\left.p \mathrm{NO}_{3}^{-}\right)$ and precipitation $\left(\mathrm{NH}_{4}^{+}-\mathrm{N}\right.$ and $\left.\mathrm{NO}_{3}^{-}-\mathrm{N}\right)$ for three land use types (e.g. urban, rural, and background) in eastern China by examining 5-year (2011-2015) in situ measurements at 27 sites. We further examined regional features of $\mathrm{N}_{\mathrm{r}}$ pollution by comparison of satellite and surface measurements of $\mathrm{NH}_{3}$ and $\mathrm{NO}_{2}$ and examined the sources of total $\mathrm{N}$ deposition over the whole region for the year 2010 using the GEOS-Chem 
model at horizontal resolution of $1 / 2^{\circ} \times 2 / 3^{\circ}$. Our major results and conclusions are as follows.

In eastern China, annual mean concentrations and dry and bulk deposition fluxes of measured $\mathrm{N}_{\mathrm{r}}$ species in air and precipitation generally ranked in the order urban $>$ rural $>$ background. The air concentrations and dry deposition were usually higher at all land use types in the northern region of eastern China than in the southern region, especially (except $\mathrm{HNO}_{3}$ ) at rural sites, for which the differences reached statistically significant levels. This is also true for the annual VWM concentrations of $\mathrm{NH}_{4}^{+}-\mathrm{N}, \mathrm{NO}_{3}^{-}-\mathrm{N}$, and TIN in precipitation, whereas bulk deposition fluxes of these species were comparable for matched land use types between the northern and southern regions.

No significant trends in the annual mean concentrations and dry and bulk deposition fluxes of measured $\mathrm{N}_{\mathrm{r}}$ species in air and precipitation were observed at almost all sites during the 2011-2015 period. Also, annual averages of these values showed non-significant changes between the 20112012 and 2013-2015 periods for all land use types. Ambient total concentrations of measured $\mathrm{N}_{\mathrm{r}}$ species showed a nonsignificant seasonal variation at all land use types, whereas individual $\mathrm{N}_{\mathrm{r}}$ species exhibited a significant seasonal variation in most cases, except for $\mathrm{NO}_{2}$ and $p \mathrm{NH}_{4}^{+}$at urban sites, and $\mathrm{HNO}_{3}$ at all land use types. Unlike air concentrations, dry deposition of total $\mathrm{N}_{\mathrm{r}}$ showed consistent and significant seasonal variation for each land use type, with the highest values in summer and the lowest values in winter. The $V_{\mathrm{d}}$ was a dominant factor influencing seasonal variations of $\mathrm{NO}_{2}, \mathrm{HNO}_{3}$, and $p \mathrm{NH}_{4}^{+}$concentrations, while seasonal variations of $\mathrm{NH}_{3}$ and $p \mathrm{NO}_{3}^{-}$are mainly influenced by their respective air concentrations. The concentrations of $\mathrm{NH}_{4}^{+}$$\mathrm{N}, \mathrm{NO}_{3}^{-}-\mathrm{N}$, and TIN in precipitation showed significant seasonal variations, ranking in the consistent order of winter $>$ spring $>$ autumn $\approx$ summer. Also, significant seasonal variations in bulk deposition were also found, following the consistent order of summer $>$ spring $\approx$ autumn $>$ winter.

Both IASI satellite-retrieved $\mathrm{NH}_{3}$ columns and OMI satellite-retrieved $\mathrm{NO}_{2}$ columns over eastern China showed higher values in the north than in the south. In addition, significant positive correlations were found between measured $\mathrm{NH}_{3}$ concentrations and retrieved $\mathrm{NH}_{3}$ columns, and between measured $\mathrm{NO}_{2}$ concentrations and columns. These results together reveal that atmospheric $\mathrm{N}_{\mathrm{r}}$ pollution is more serious in the northern region, and also suggest that satellite retrievals of $\mathrm{NH}_{3}$ and $\mathrm{NO}_{2}$ columns can provide useful information on spatial concentration variability of these two key $\mathrm{N}_{\mathrm{r}}$ species at a regional or national scale. Weak correlations between IASI_NH $\mathrm{NH}_{3}$ observations and surface $\mathrm{NH}_{3}$ measurements were found at most selected sites, suggesting that IASI_NH 3 observations in their current state are not as readily used to accurately track temporal variability in surface $\mathrm{NH}_{3}$ concentrations.

Ammonia is currently not included in China's emission control policies of air pollution precursors, although the ne- cessity of mitigation has been the subject of discussion during recent years. Across all urban and rural sites, the slopes of the regression relation between $p \mathrm{NH}_{4}^{+}$and the sum of $p \mathrm{SO}_{4}^{2-}$ and $p \mathrm{NO}_{3}^{-}$were both smaller than unity, indicating that controlling $\mathrm{NH}_{3}$ emissions not only can directly reduce ambient $\mathrm{NH}_{3}$ concentrations, but also lower the formation of $p \mathrm{NH}_{4}^{+}$and $p \mathrm{NO}_{3}^{-}$. Fertilizer use contributed $36 \%$ of the total $\mathrm{N}$ deposition over eastern China, suggesting reducing $\mathrm{NH}_{3}$ emissions from fertilizer application would be an effective strategy for reducing $\mathrm{N}$ deposition. Overall, our findings reveal persistent serious $\mathrm{N}_{\mathrm{r}}$ pollution during the 12th FYP period despite implementation of current emission controls, and highlight the importance of $\mathrm{NH}_{3}$ emission controls for mitigating future atmospheric $\mathrm{N}_{\mathrm{r}}$ concentrations and deposition in eastern China.

Data availability. The data used in this study are available from the corresponding author upon request (liu310@cau.edu.cn).

\section{The Supplement related to this article is available online at https://doi.org/10.5194/acp-18-10931-2018- supplement.}

Author contributions. XJL, FZ, and WX designed the research; WX, XSL, JS, and LLu conducted the field work; LLi, XZ, and MC prepared IASI_NH $\mathrm{NH}_{3}$ and $\mathrm{OMI} \mathrm{NO}_{2}$ products; YHZ and LZ conducted model simulations; $\mathrm{XZ}$ and $\mathrm{BG}$ provided the ammonia emission data; $\mathrm{YZ}$ provided the emission data of nitrogen dioxide and sulfur dioxide; WX, LLi, MC, YL, and YHZ performed the data analysis and prepared the figures and tables; WX and XJL wrote the paper with comments from JLC, ZF, and YP.

Competing interests. The authors declare that they have no conflict of interest.

Acknowledgements. This study was supported by the National Key R\&D Program of China (2017YFC0210101, 2017YFC0210106, 2014BC954202), the National Natural Science Foundation of China (41705130, 41425007, 31421092) as well as the National Ten-thousand Talents Program of China (Xuejun Liu). The authors thank all staff at the study sites (listed in Table S1, Supplement) for their cooperation during sample collection. We also thank two anonymous reviewers for insightful comments regarding the improvement of the paper.

Leiming Zhang

Reviewed by: two anonymous referees

\section{References}

Aguillaume, L., Rodrigo, A., and Avila, A.: Long-term effects of changing atmospheric pollution on throughfall, bulk deposition 
and streamwaters in a Mediterranean forest, Sci. Total Environ., 544, 919-928, https://doi.org/10.1016/j.scitotenv.2015.12.017, 2016.

Allen, A. G., Harrison, R. M., and Erisman, J. W.: Field measurements of the dissociation of ammonium nitrate and ammonium chloride aerosols, Atmos. Environ., 23, 1591-1599, 1989.

Atkins, D. H. F. and Lee, D. S.: Spatial and temporal variation of rural nitrogen dioxide concentrations across the United Kingdom, Atmos. Environ., 29, 223-239, 1995.

Bobbink, R., Hicks, K., Galloway, J., Spranger, T., Alkemade, R., Ashmore, M., Bustamante, M., Cinderby, S., Davidson, E., and Dentener, F.: Global assessment of nitrogen deposition effects on terrestrial plant diversity: a synthesis, Ecol. Appl., 20, 30-59, 2010.

Boersma, K. F., Eskes, H. J., Veefkind, J. P., Brinksma, E. J., van der A, R. J., Sneep, M., van den Oord, G. H. J., Levelt, P. F., Stammes, P., Gleason, J. F., and Bucsela, E. J.: Near-real time retrieval of tropospheric $\mathrm{NO}_{2}$ from OMI, Atmos. Chem. Phys., 7, 2103-2118, https://doi.org/10.5194/acp-7-2103-2007, 2007.

Cao, J. J., Zhang, T., Chow, J. C., Watson, J. G., Wu, F., and Li, H.: Characterization of atmospheric ammonia over Xi' an, China, Aerosol Air Qual. Res., 9, 277-289, 2009.

Chang, Y. H., Liu, X. J., Deng, C. R., Dore, A. J., and Zhuang, G. S.: Source apportionment of atmospheric ammonia before, during, and after the 2014 APEC summit in Beijing using stable nitrogen isotope signatures, Atmos. Chem. Phys., 16, 11635-11647, https://doi.org/10.5194/acp-16-11635-2016, 2016.

Dammers, E., Palm, M., Van Damme, M., Vigouroux, C., Smale, D., Conway, S., Toon, G. C., Jones, N., Nussbaumer, E., Warneke, T., Petri, C., Clarisse, L., Clerbaux, C., Hermans, C., Lutsch, E., Strong, K., Hannigan, J. W., Nakajima, H., Morino, I., Herrera, B., Stremme, W., Grutter, M., Schaap, M., Wichink Kruit, R. J., Notholt, J., Coheur, P. F., and Erisman, J. W.: An evaluation of IASI-NH $\mathrm{N}_{3}$ with ground-based Fourier transform infrared spectroscopy measurements, Atmos. Chem. Phys., 16, 10351-10368, https://doi.org/10.5194/acp-16-10351-2016, 2016.

Erisman, J. W., Grennfelt, P., and Sutton, M.: The European perspective on nitrogen emission and deposition. Environ. Int., 29, 311-325, https://doi.org/10.1016/S0160-4120(02)00162-9, 2003.

Fagerli, H. and Aas, W.: Trends of nitrogen in air and precipitation: model results and observations at EMEP sites in Europe, 1980-2003, Environ. Pollut., 154, 448-461, https://doi.org/10.1016/j.envpol.2008.01.024, 2008.

Fenn, M. E., Baron, J. S., Allen, E. B., Rueth, H. M., Nydick, K. R., Geiser, L., Bowman, W. D., Sickman, J. O., Meixner, T., Johnson, D. W., and Neitlich, P.: Ecological Effects of Nitrogen Deposition in the Western United States, BioScience, 53, 404-420, https://doi.org/10.1641/00063568(2003)053[0404:EEONDI]2.0.CO;2, 2003.

Fowler, D., Smith, R., Muller, J., Cape, J. N., Sutton, M., Erisman, J. W., and Fagerli, H.: Long term trends in sulphur and nitrogen deposition in Europe and the cause of non-linearities, Water Air Soil Pollut., 7, 41-47, https://doi.org/10.1007/s11267-006-9102$\mathrm{x}, 2007$.

Fowler, D., Coyle, M., Skiba, U., Sutton, M. A., Cape, J. N., Reis, S., Sheppard, L. J., Jenkins, A., Grizzetti, B., Galloway, J. N., Vitousek, P., Leach, A., Bouwman, A. F., Butterbach-Bahl, K., Dentener, F., Stevenson, D., Amann, M., and Voss, M.: The global nitrogen cycle in the twenty-first century, Philos. T. R. Soc. B, 368, 20130164, https://doi.org/10.1098/rstb.2013.0164, 2013.

Fuzzi, S., Baltensperger, U., Carslaw, K., Decesari, S., van Der Gon, H. D., Facchini, M. C., Fowler, D., Koren, I., Langford, B., Lohmann, U., Nemitz, E., Pandis, S., Riipinen, I., Rudich, Y., Schaap, M., Slowik, J. G., Spracklen, D. V., Vignati, E., Wild, M., Williams, M., and Gilardoni, S.: Particulate matter, air quality and climate: lessons learned and future needs, Atmos. Chem. Phys., 15, 8217-8299, https://doi.org/10.5194/acp15-8217-2015, 2015.

Galloway, J. N., Townsend, A. R., Erisman, J. W., Bekunda, M., Cai, Z., Freney, J. R., Martinelli, L. A., Seitzinger, S. P., and Sutton, M. A.: Transformation of the Nitrogen Cycle: Recent trends, questions, and potential solutions, Science, 320, 889-892, https://doi.org/10.1126/science.1136674, 2008.

Ge, B. Z., Wang, Z. F., Xu, X. B., Wu, J. B., Yu, X. L., and $\mathrm{Li}, \mathrm{J}$. : Wet deposition of acidifying substances in different regions of China and the rest of East Asia: modeling with updated NAQPMS, Environ. Pollut., 187, 10-21, https://doi.org/10.1016/j.envpol.2013.12.014, 2014.

Gilbert, R. O.: Statistical methods for environmental pollution monitoring, John Wiley \& Sons, 1987.

Gu, B. J., Sutton, M. A., Chang, S. X., Ge, Y., and Jie, C.: Agricultural ammonia emissions contribute to China's urban air pollution, Front. Ecol. Environ., 12, 265-266, https://doi.org/10.1890/14.WB.007, 2014.

Guo, S., Hu, M., Zamora, M. L., Peng, J. F., Shang, D. J., Zheng, J., Du, Z. F., Wu, Z. J., Shao, M., and Zeng, L. M.: Elucidating severe urban haze formation in China, P. Natl. Acad. Sci. USA, 111, 17373, https://doi.org/10.1073/pnas.1419604111, 2014.

Han, X., Zhang, M. G., Skorokhod, A., and Kou, X. X.: Modeling dry deposition of reactive nitrogen in China with RAMS-CMAQ, Atmos. Environ., 166, 47-61, https://doi.org/10.1016/j.atmosenv.2017.07.015, 2017.

He, N. P., Zhu, J. X., and Wang, Q. F.: Uncertainty and perspectives in studies of atmospheric nitrogen deposition in China: A response to Liu et al. (2015), Sci. Total Environ., 520, 302-304, https://doi.org/10.1016/j.scitotenv.2015.03.063, 2015.

Huang, P., Zhang, J. B., Xin, X. L., Zhu, A. N., Zhang, C. Z., Ma, D. H., Zhu, Q. G., Yang, S., and Wu, S. J.: Proton accumulation accelerated by heavy chemical nitrogen fertilization and its long-term impact on acidifying rate in a typical arable soil in the Huang-Huai-Hai Plain, J. Integr. Agric., 14, 148-157, 2015.

Huang, R. J., Zhang, Y., Bozzetti, C., Ho, K. F., Cao, J. J., Han, Y., Daellenbach, K. R., Slowik, J. G., Platt, S. M., Canonaco, F., Zotter, P., Wolf, R., Pieber, S. M., Bruns, E. A., Crippa, M., Ciarelli, G., Piazzalunga, A., Schwikowski, M., Abbaszade, G., SchnelleKreis, J., Zimmermann, R., An, Z., Szidat, S., Baltensperger, U., El Haddad, I., and Prevot, A. S.: High secondary aerosol contribution to particulate pollution during haze events in China, Nature, 514, 218-222, https://doi.org/10.1038/nature13774, 2014.

Huang, X., Song, Y., Li, M. M., Li, J. F., Huo, Q., Cai, X. H., Zhu, T., Hu, M., and Zhang, H. S: A high-resolution ammonia emission inventory in China, Global Biogeochem. Cy., 26, GB1030, https://doi.org/10.1029/2011GB004161, 2012.

Ianniello, A., Spataro, F., Esposito, G., Allegrini, I., Rantica, E., Ancora, M. P., Hu, M., and Zhu, T.: Occurrence of gas phase 
ammonia in the area of Beijing (China), Atmos. Chem. Phys., 10, 9487-9503, https://doi.org/10.5194/acp-10-9487-2010, 2010.

Jia, B., Wang, Y., Yao, Y., and Xie, Y.: A new indicator on the impact of large-scale circulation on wintertime particulate matter pollution over China, Atmos. Chem. Phys., 15, 11919-11929, https://doi.org/10.5194/acp-15-11919-2015, 2015.

Jia, Y. L., Yu, G. R., He, N. P., Zhan, X. Y., Fang, H. J., Sheng, W. P., Zuo, Y., Zhang, D. Y., and Wang, Q. F.: Spatial and decadal variations in inorganic nitrogen wet deposition in China induced by human activity, Sci. Rep., 4, 3763, https://doi.org/10.1038/srep03763, 2014.

Jia, Y. L., Yu, G. R., Gao, Y. N., He, N. P., Wang, Q. F., Jiao, C. C., and Zuo, Y.: Global inorganic nitrogen dry deposition inferred from ground and space-based measurements, Sci. Rep., 6, 19810, https://doi.org/10.1038/srep19810, 2016.

Ju, X. T., Xing, G. X., Chen, X. P., Zhang, S. L., Zhang, L. J., Liu, X. J., Cui, Z. L., Yin, B., Christie, P., Zhu, Z. L., and Zhang, F. S.: Reducing environmental risk by improving $\mathrm{N}$ management in intensive Chinese agricultural systems, P. Natl. Acad. Sci. USA, 106, 3041-3046, https://doi/10.1073/pnas.0902655106, 2009.

Kanakidou, M., Myriokefalitakis, S., Daskalakis, N., and Fanourgakis, G.: Past, present, and future atmospheric nitrogen deposition, J. Atmos. Sci., 73, 160303130433005 , https://doi.org/10.1175/JAS-D-15-0278.s1, 2016.

Karlsson, G. P., Akselsson, C., Hellsten, S., and Karlsson, P. E.: Reduced European emissions of $\mathrm{S}$ and $\mathrm{N}$ effects on air concentrations, deposition and soil water chemistry in Swedish forests, Environ. Pollut. 159, 3571-3582, https://doi.org/10.1016/j.envpol.2011.08.007, 2011.

Khoder, M. I.: Atmospheric conversion of sulfur dioxide to particulate sulfate and nitrogen dioxide to particulate nitrate and gaseous nitric acid in an urban area, Chemosphere, 49, 675-684, 2002.

Krotkov, N. A., Mclinden, C. A., Li, C., Lamsal, L. N., Celarier, E. A., Marchenko, S. V., Swartz, W. H., Bucsela, E. J., Joiner, J., Duncan, B. N., Boersma, K. F., Veefkind, J. P., Levelt, P. F., Fioletov, V. E., Dickerson, R. R., He, H., Lu, Z. F., and Streets, D. G.: Aura OMI observations of regional $\mathrm{SO}_{2}$ and $\mathrm{NO}_{2}$ pollution changes from 2005 to 2015, Atmos. Chem. Phys., 16, 46054629, https://doi.org/10.5194/acp-16-4605-2016, 2016.

Kurokawa, J., Ohara, T., Morikawa, T., Hanayama, S., JanssensMaenhout, G., Fukui, T., Kawashima, K., and Akimoto, H.: Emissions of air pollutants and greenhouse gases over Asian regions during 2000-2008: Regional Emission inventory in Asia (REAS) version 2, Atmos. Chem. Phys., 13, 11019-11058, https://doi.org/10.5194/acp-13-11019-2013, 2013.

Li, H., Zhang, Q., Zheng, B., Chen, C., Wu, N., Guo, H., Zhang, Y., Zheng, Y., Li, X., and He, K.: Nitrate-driven urban haze pollution during summertime over the North China Plain, Atmos. Chem. Phys., 18, 5293-5306, https://doi.org/10.5194/acp18-5293-2018, 2018.

Li, Y., Niu, S., and Yu, G.: Aggravated phosphorus limitation on biomass production under increasing nitrogen loading: a meta-analysis, Global Change Biol., 22, 934-943, https://doi.org/10.1111/gcb.13125, 2016.

Liang, X., Zou, T., Guo, B., Li, S., Zhang, H. Z., Zhang, S. Y., Huang, H., and Chen, S. X.: Assessing Beijing's PM $_{2.5}$ pollution: severity, weather impact, APEC and winter heating, Proc. R. Soc. A., 471, 20150257, https://doi.org/10.1098/rspa.2015.0257, 2015.
Liu, F., Beirle, S., Zhang, Q., van der A, R. J., Zheng, B., Tong, D., and He, K.: $\mathrm{NO}_{x}$ emission trends over Chinese cities estimated from OMI observations during 2005 to 2015, Atmos. Chem. Phys., 17, 9261-9275, https://doi.org/10.5194/acp-179261-2017, 2017.

Liu, L., Zhang, X. Y., Zhang, Y., Xu, W., Liu, X. J., Zhang, X. M., Feng, J. L., Chen, X. R., Zhang, Y. H., Lu, X. H., Wang, S. Q., Zhang, W. T., and Zhao, L. M.: Dry particulate nitrate deposition in China, Environ. Sci. Techno., 51, 5572, https://doi.org/10.1021/acs.est.7b00898, 2017a.

Liu, L., Zhang, X., Xu, W., Liu, X., Li, Y., Lu, X., Zhang, Y., and Zhang, W.: Temporal characteristics of atmospheric ammonia and nitrogen dioxide over China based on emission data, satellite observations and atmospheric transport modeling since 1980, Atmos. Chem. Phys., 17, 9365-9378, https://doi.org/10.5194/acp17-9365-2017, $2017 \mathrm{~b}$.

Liu, X. J., Duan, L., Mo, J. M., Du, E. Z., Shen, J. L., Lu, X. K., Zhang, Y., Zhou, X. B., He, C. E., and Zhang, F. S.: Nitrogen deposition and its ecological impact in China: An overview, Environ. Pollut., 159, 2251-2264, https://doi.org/10.1016/j.envpol.2010.08.002, 2011.

Liu, X. J., Zhang, Y., Han, W. X., Tang, A., Shen, J. L., Cui, Z. L., Vitousek, P., Erisman, J. W., Goulding, K., Christie, P., Fangmeier, A., and Zhang, F. S.: Enhanced nitrogen deposition over China, Nature, 494, 459-462, https://doi.org/10.1038/nature11917, 2013.

Liu, X. J., Vitousek, P., Chang, Y. H., Zhang, W. F., Matson, P., and Zhang, F. S.: Evidence for a historic change occurring in China, Environ. Sci. Technol., 50, 505-506, https://doi.org/10.1021/acs.est.5b05972, 2016.

Lu, C. Q. and Tian, H. Q.: Spatial and temporal patterns of nitrogen deposition in China: Synthesis of observational data, J. Geophys. Res., 112, D22S05, https://doi.org/10.1029/2006JD007990, 2007.

Lu, C. Q. and Tian, H. Q.: Half-century nitrogen deposition increase across China: A gridded time-series data set for regional environmental assessments, Atmos. Environ., 97, 68-74, https://doi.org/10.1016/j.atmosenv.2014.07.061, 2014.

Marchetto, A., Rogora, M., and Arisci, S.: Trend analysis of atmospheric deposition data: A comparison of statistical approaches, Atmos. Environ., 64, 95-102, 2013.

Meng, Z. Y., Xu, X. B., Wang, T., Zhang, X. Y., Yu, X. L., Wang, S. F., Lin, W. L., Chen, Y. Z., Jiang, Y. A., and An, X. Q.: Ambient sulfur dioxide, nitrogen dioxide, and ammonia at ten background and rural sites in China during 2007-2008, Atmos. Environ., 44, 2625-2631, 2008.

Meng, Z. Y., Xu, X. B., Lin, W. L., Ge, B. Z., Xie, Y. L., Song, B., Jia, S. H., Zhang, R., Peng, W., Wang, Y., Cheng, H. B., Yang, W., and Zhao, H.: Role of ambient ammonia in particulate ammonium formation at a rural site in the North China Plain, Atmos. Chem. Phys., 18, 167-184, https://doi.org/10.5194/acp-18-1672018, 2018.

MEPC (Ministry of Environmental Protection of the People's Republic of China): Report on Environmental Quality in China, 2010, available at: http://jcs.mep.gov.cn/hjzl/zkgb/2010zkgb/ 201106/t20110602_211579.htm, last access: 3 June 2011.

Miyazaki, K., Eskes, H., Sudo, K., Boersma, K. F., Bowman, K., and Kanaya, Y.: Decadal changes in global surface $\mathrm{NO}_{x}$ emissions from multi-constituent satellite data assimilation, Atmos. 
Chem. Phys., 17, 807-837, https://doi.org/10.5194/acp-17-8072017, 2017.

Pan, Y. P., Wang, Y. S., Tang, G. Q., and Wu, D.: Wet and dry deposition of atmospheric nitrogen at ten sites in Northern China, Atmos. Chem. Phys., 12, 6515-6535, https://doi.org/10.5194/acp12-6515-2012, 2012.

Pan, Y. P., Wang, Y. S., Zhang, J. K., Liu, Z. R., Wang, L. L., Tian, S. L., Tang, G. Q., Gao, W. K., Ji, D. S., and Song, T.: Redefining the importance of nitrate during haze pollution to help optimize an emission control strategy, Atmos. Environ., 141, 197202, https://doi.org/10.1016/j.atmosenv.2016.06.035, 2016.

Pinder, R. W., Walker, J. T., Bash, J. O., Cady-Pereira, K. E., Henze, D. K., Luo, M. Z., Osterman, G. B., and Shephard, M. W.: Quantifying spatial and seasonal variability in atmospheric ammonia with in situ and space-based observations, Geophys. Res. Lett., 38, L04802, https://doi.org/10.1029/2010GL046146, 2011.

Russell, A. R., Valin, L. C., and Cohen, R. C.: Trends in OMI $\mathrm{NO}_{2}$ observations over the United States: effects of emission control technology and the economic recession, Atmos. Chem. Phys., 12, 12197-12209, https://doi.org/10.5194/acp-12-121972012, 2012.

Salmi, T., Maatta, A., Anttila, P., Ruoho-Airola, T., and Amnell, T.: Detecting trends of annual values of atmospheric pollutants by the Mann-Kendall test and Sen's slope estimates - the Excel template application MAKESENS. Publications on Air Quality No. 31, Finnish Meteorological Institute, Helsinki, Finland, 2002.

Seinfeld, J. H. and Pandis, S. N.: Atmospheric chemistry and physics: from air pollution to climate change, 2nd Edn., Wiley Interscience, New Jersey, 2006.

She, W.: Hu Huanyong: father of China's population geography, China Popul. Today, 15, 1-20, 1998.

Souri, A. H., Choi, Y., Jeon, W., Woo, J.-H., Zhang, Q., and Kurokawa, J.-i.: Remote sensing evidence of decadal changes in major tropospheric ozone precursors over East Asia, J. Geophys. Res., 122, 2474-2492, https://doi.org/10.1002/2016JD025663, 2017.

Tang, Y. S., Simmons, I., van Dijk, N., Di Marco, C., Nemitz, E., Dammgen, U., Gilke, K., Djuricic, V., Vidic, S., and Gliha, Z.: European scale application of atmospheric reactive nitrogen measurements in a low-cost approach to infer dry deposition fluxes, Agr. Ecosyst. Environ., 133, 183-195, https://doi.org/10.1016/j.agee.2009.04.027, 2009.

Theil, H.: A Rank-Invariant Method of Linear and Polynomial Regression Analysis, in: Henri Theil's Contributions to Economics and Econometrics, edited by: Raj, B. and Koerts, J., Advanced Studies in Theoretical and Applied Econometrics, Springer Netherlands, 345-381, 1992.

Tian, S. L., Pan, Y. P., Liu, Z. R., Wen, T. X., and Wang, Y. S.: Size-resolved aerosol chemical analysis of extreme haze pollution events during early 2013 in urban Beijing, China, J. Hazard. Mater., 279, 452-460, https://doi.org/10.1016/j.jhazmat.2014.07.023, 2014.

Van Damme, M., Clarisse, L., Dammers, E., Liu, X., Nowak, J. B., Clerbaux, C., Flechard, C. R., Galylacaux, C., Xu, W., and Neuman, J. A.: Towards validation of ammonia $\left(\mathrm{NH}_{3}\right)$ measurements from the IASI satellite, Atmos. Meas. Tech., 8, 15751591, https://doi.org/10.5194/amt-8-1575-2015, 2015.

van der A, R. J., Mijling, B., Ding, J., Koukouli, M. E., Liu, F., Li, Q., Mao, H., and Theys, N.: Cleaning up the air: effectiveness of air quality policy for $\mathrm{SO}_{2}$ and $\mathrm{NO}_{x}$ emissions in China, Atmos. Chem. Phys., 17, 1775-1789, https://doi.org/10.5194/acp17-1775-2017, 2017.

Vet, R., Artz, R. S., Carou, S., Shaw, M., Ro, C.-U., Aas, W., Baker, A., Bowersox, V. C., Dentener, F., Galy-Lacaux, C., Hou, A., Pienaar, J. J., Gillett, R., Forti, M. C., Gromov, S., Hara, H., Khodzher, T., Mahowald, N. M., Nickovic, S., Rao, P. S. P., and Reid, N. W.: A global assessment of precipitation chemistry and deposition of sulfur, nitrogen, sea salt, base cations, organic acids, acidity and pH, and phosphorus, Atmos. Environ., 93, 3 100, https://doi.org/10.1016/j.atmosenv.2013.10.060, 2014.

Walker, J. T., Whitall, D. R., Robarge, W., and Paerl, H. W.: Ambient ammonia and ammonium aerosol across a region of variable ammonia emission density, Atmos. Environ., 38, 1235-1246, 2004.

Wang, G. H., Zhang, R. Y., Gomez, M. E., Yang, L. X., Zamora, M. L., Hu, M., Lin, Y., Peng J. F., Guo, S., Meng, J. J., Li, J. J., Cheng, C .L., Hu, T. F., Ren, Y. Q., Wang, Y. S., Gao, J., Cao, J. J., An, Z. S., Zhou, W. J., Li, G. H., Wang, J. Y., Tian, P. F., Marrero-Ortiz, W., Secrest J., Du, Z. F., Zheng, J., Shang, D. J., Zeng, L. M., Shao, M., Wang, W. G., Huang, Y., Wang, Y., Zhu, Y. J., Li, Y. X., Hu, J. X., Pan, B. W., Cai, L., Cheng, Y. T., Ji, Y. M., Zhang, F., Rosenfeld, D., Liss, P. S., Duce, R. A., Kolb, C. E., and Molina, M. J.: Persistent sulfate formation from London Fog to Chinese haze, P. Natl. Acad. Sci. USA, 113, 13630, https://doi.org/10.1073/pnas.1616540113, 2016.

Wang, S. X., Xing, J., Jang, C. R., Zhu, Y., Fu, J. S., and Hao, J. M.: Impact assessment of ammonia emissions on inorganic aerosols in East China using response surface modeling technique, Environ. Sci. Techno., 45, 9293-9300, https://doi.org/10.1021/es2022347, 2011.

Wen, L., Chen, J. M., Yang, L. X., Wang, X. F., Xu, C. H., Sui, X., Yao, L., Zhu, Y. H., Zhang, J. M., Zhu, T., and Wang, W. X.: Enhanced formation of fine particulate nitrate at a rural site on the North China Plain in summer: The important roles of ammonia and ozone, Atmos. Environ., 101, 294-302, https://doi.org/10.1016/j.atmosenv.2014.11.037, 2015.

Wesely, M. L.: Parameterization of surface resistances to gaseous dry deposition in regional-scale numerical-models, Atmos. Environ., 23, 1293-1304, 1989.

Whitburn, S., Van Damme, M., Clarisse, L., Bauduin, S., Heald, C. L., Hadji-Lazaro, J., Hurtmans, D., Zondlo, M. A., Clerbaux, C., and Coheur, P. F.: A flexible and robust neural network IASINH3 retrieval algorithm, J. Geophys. Res.-Atmos., 121, 6581-6599, https://doi.org/10.1002/2016JD024828, 2016.

Xia, Y. M., Zhao, Y., and Nielsen, C. P.: Benefits of China's efforts in gaseous pollutant control indicated by the bottom-up emissions and satellite observations 2000-2014, Atmos. Environ., 136, 43-53, https://doi.org/10.1016/j.atmosenv.2016.04.013, 2016.

Xu, W., Luo, X. S., Pan, Y. P., Zhang, L., Tang, A. H., Shen, J. L., Zhang, Y., Li, K. H., Wu, Q. H., Yang, D. W., Zhang, Y. Y., Xue, J., Li, W. Q., Li, Q. Q., Tang, L., Lu, S. H., Liang, T., Tong, Y. A., Liu, P., Zhang, Q., Xiong, Z. Q., Shi, X. J., Wu, L. H., Shi, W. Q., Tian, K., Zhong, X. H., Shi, K., Tang, Q. Y., Zhang, L. J., Huang, J. L., He, C. E., Kuang, F. H., Zhu, B., Liu, H., Jin, X., Xin, Y. J., Shi, X. K., Du, E. Z., Dore, A. J., Tang, S., Collett Jr., J. L., Goulding, K., Sun, Y. X., Ren, J., Zhang, F. S., and Liu, X. J.: Quantifying atmospheric nitrogen deposition through 
a nationwide monitoring network across China, Atmos. Chem. Phys., 15, 12345-12360, https://doi.org/10.5194/acp-15-123452015, 2015.

Xu, W., Wu, Q. H., Liu, X. J., Tang, A. H., Dore, A. J., and Heal, M. R.: Characteristics of ammonia, acid gases, and $\mathrm{PM}_{2.5}$ for three typical land-use types in the North China Plain, Environ. Sci. Pollut. Res., 23, 1158-1172, https://doi.org/10.1007/s11356015-5648-3, 2016.

Xu, W., Song, W., Zhang, Y., Liu, X., Zhang, L., Zhao, Y., Liu, D., Tang, A., Yang, D., Wang, D., Wen, Z., Pan, Y., Fowler, D., Collett Jr., J. L., Erisman, J. W., Goulding, K., Li, Y., and Zhang, F.: Air quality improvement in a megacity: implications from 2015 Beijing Parade Blue pollution control actions, Atmos. Chem. Phys., 17, 31-46, https://doi.org/10.5194/acp-17-31-2017, 2017.

Xu, W., Zhao, Y. H., Liu, X. J., Dore, A. J., Zhang, L., Liu, L., and Cheng, M.: Atmospheric nitrogen deposition in the Yangtze River basin: Spatial pattern and source attribution, Environ. Pollut., 232, 546-555, https://doi.org/10.1016/j.envpol.2017.09.086, 2018.

Yang, F., Tan, J., Zhao, Q., Du, Z., He, K., Ma, Y., Duan, F., Chen, G., and Zhao, Q.: Characteristics of $\mathrm{PM}_{2.5}$ speciation in representative megacities and across China, Atmos. Chem. Phys., 11, 5207-5219, https://doi.org/10.5194/acp-11-5207-2011, 2011.

Yang, Y. H., Li, P., He, H. L., Zhao, X., Datta, A., Ma, W. H., Zhang, Y., Liu, X. J., Han, W. X., Wilson, M. C., and Fang, J. Y.: Long-term changes in soil $\mathrm{pH}$ across major forest ecosystems in China, Geophys. Res. Lett., 42, 933-940, https://doi.org/10.1002/2014GL062575, 2015.

Zhang, L., Chen, Y. F., Zhao, Y. H., Henze, D. K., Zhu, L. Y., Song, Y., Paulot, F., Liu, X. J., Pan, Y. P., and Huang, B. X.: Agricultural ammonia emissions in China: reconciling bottomup and top-down estimates, Atmos. Chem. Phys., 18, 339-355, https://doi.org/10.5194/acp-18-339-2018, 2018.
Zhang, L. M., Gong, S. L., Padro, J., and Barrie, L.: A size-segregated particle dry deposition scheme for an atmospheric aerosol module, Atmos. Environ., 35, 549-560, https://doi.org/10.1016/s1352-2310(00)00326-5, 2001.

Zhang, Q., Duan, F. K., He, K. B., Ma, Y. L., Li, H. Y., Kimoto, T., and Zheng, A. H.: Organic nitrogen in $\mathrm{PM}_{2.5}$ in Beijing, Front. Environ. Sci. Eng., 9, 1004-1014, https://doi.org/10.1007/s11783-015-0799-5, 2015.

Zhang, X. M., Wu, Y. Y., Liu, X. J., Reis, S., Jin, J. X., Dragosits, U., Damme, Van M., Clarisse, L., Whitburn, S., and Coheur, P. F.: Ammonia emissions may be substantially underestimated in China, Environ. Sci. Technol., 51, 12089-12096, https://doi.org/10.1021/acs.est.7b02171, 2017.

Zhao, Y., Nielsen, C. P., Lei, Y., McElroy, M. B., and Hao, J.: Quantifying the uncertainties of a bottom-up emission inventory of anthropogenic atmospheric pollutants in China, Atmos. Chem. Phys., 11, 2295-2308, https://doi.org/10.5194/acp-112295-2011, 2011.

Zhao, Y., Zhang, L., Pan, Y., Wang, Y., Paulot, F., and Henze, D. K.: Atmospheric nitrogen deposition to the northwestern Pacific: seasonal variation and source attribution, Atmos. Chem. Phys., 15, 10905-10924, https://doi.org/10.5194/acp-15-109052015, 2015.

Zhao, Y., Zhang, L., Chen, Y. F., Liu, X. J., Xu, W., Pan, Y. P., and Duan, L.: Atmospheric nitrogen deposition to China: a model analysis on nitrogen budget and critical load exceedance, Atmos. Environ., 153, 32-40, https://doi.org/10.1016/j.atmosenv.2017.01.018, 2017.

Zhu, J. X., He, N. P., Wang, Q. F., Yan, G. F., Wen, D., Yu, G. R., and Jia, Y. L.: The composition, spatial patterns, and influencing factors of atmospheric wet nitrogen deposition in Chinese terrestrial ecosystems, Sci. Total Environ., 511, 777-785, https://doi.org/10.1016/j.scitotenv.2014.12.038, 2015. 